\title{
PROCEDURES FOR TESTING, RATING, AND ESTIMATING THE SEASONAL PERFORMANCE OF ENGINE-DRIVEN HEAT PUMP SYSTEMS
}

B. R. Maxwell

Building Thermal and Service Systems Division Center for Building Technology National Engineering Laboratory National Bureau of Standards Washington, D.C. 20234

September 1979

Sponsored by:

The Department of Energy

20 Massachusetts Ave., N.W.

Washington, D.C. 20585

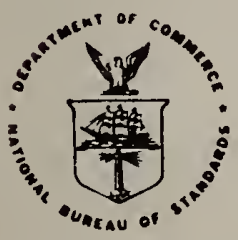

U.S. DEPARTMENT OF COMMERCE, Juanita M. Kreps, Secretary Luther H. Hodges, Jr., Under Secretary Jordan J. Baruch, Assistant Secretary for Science and Technology NATIONAL BUREAU OF STANDARDS, Ernest Ambler, Director 


\section{ABSTRACT}

A generic test and rating procedure is developed for heat engine-driven air-to-air heat pump systems. The procedures are classified according to whether the systems have single-speed, two-speed, or variable-speed capability, and whether they are operating in the heating or cooling mode. The test requirements generally consist of a series of steadystate tests to establish the impact of outdoor temperature on performance, two or more part-load (cyclic) tests to determine the effect of "on-off" cycling, two steady-state intermedlate speed tests to determine part-speed performance, and a single frost accumulation test to estimate the effect of frost. A generalized calculation and rating procedure is developed. The system is rated in both modes based upon its steady-state performance at the ARI standard rating points, its seasonal performance factor, and its seasonal operating cost. A frost degradation coefficient is also established. The seasonal parameters are based upon either a residential or commercial/industrial building application which is located in efther a generalized northern or southern climate.

Key Words: Building heating and cooling; engine-driven heat pump; heat pump; heating and cooling equipment; heating, ventilating and air conditioning. 



\section{NOMENCLATURE}

BHC

BHH

$B L\left(T_{j}\right)$

$\mathrm{C}_{\mathrm{D}}$

$C_{\text {def }}$

$\mathrm{C}_{\mathrm{E}}$

$\mathrm{C}_{\mathrm{F}}$

$\mathrm{C}_{\mathrm{S}}$

cpa

COP

$\operatorname{COP}_{\text {cyc }}\left(\mathrm{T}_{j}\right)$

$\mathrm{COP}_{\text {def }}(32)$

$\operatorname{COP}_{s s}\left(\mathrm{~T}_{j}\right)$

$\mathrm{E}_{\text {cyc }}\left(\mathrm{T}_{\text {cyc }}\right)$

$E_{\text {def }}(32)$

$\dot{E}_{s s}\left(\mathrm{~T}_{j}\right)$

$\mathrm{E}_{\mathrm{T}}$

$E_{T}\left(T_{j}\right)$

$E_{T}^{\prime}\left(T_{j}\right)$

HDT

j

LHV

$\dot{\mathrm{m}}_{\mathrm{f}}\left(\mathrm{T}_{\mathrm{j}}\right)$

n

$n_{j}$

$\mathrm{N}$

$\mathrm{N}^{\mathrm{O}}$
Average total bin hours for cooling, (hrs)

Average total bin hours for heating, (hrs)

Building load at dry-bulb temperature $T_{j}$, (Btu/hr)

Part-load degradation coefficient

Frost degradation coefficient

Electric energy cost, $(\$ / \mathrm{kWh})$

Engine fuel cost, ( $\$ / \mathrm{kBtu})$

Supplemental energy cost, $(\$ / k B t u)$

Specific heat of air-water mixture, $c_{\mathrm{pa}}=.24+.444 \mathrm{~W}_{\mathrm{n}}$, (IBm - F)

Cyclic coefficient of performance for one "off"/"on" cycle

Cyclic coefficient of performance at temperature $\mathrm{T}_{j}$

Coefficient of performance under frost conditions

Steady-state coefficient of performance at temperature $\mathrm{T}_{j}$

Total input electric energy during one "off"/"on" cycle at ' cyc' (watt-hr)

Total input electric energy during the frost accumulation and defrost test, (watt-hr)



Total electric and fuel energy required during a season, (Btu)

Total input electric and fuel energy in the $j$ th temperature bin, (Btu)

Cost of total input electric and fuel energy in the $j$ th temperature bin (\$)

Heating design temperature, (F)

Bin number

Lower heating value of fuel (Btu/Ibm or Btu/ft ${ }^{3}$ )

Fuel mass (or volume) flow rate ( $1 \mathrm{bm} / \mathrm{hr}$ or $\mathrm{ft}^{3} / \mathrm{hr}$ )

Total number of non-zero temperature bins

Number of hours in the $j$ th temperature bin

Total heating or cooling season temperature bin hours, (hrs)

Minimum compressor speed, (rpm) 


\begin{tabular}{|c|c|}
\hline $\mathrm{N}^{1}$ & Maximum compressor speed, (rpm) \\
\hline $\mathrm{N}^{i}$ & Intermediate compressor speed, (rpm) \\
\hline $\operatorname{PLF}\left(X\left(T_{j}\right)\right)$ & Heating or cooling part-load factor \\
\hline Q & Total heating or cooling done during a season, (Btu) \\
\hline$Q\left(T_{j}\right)$ & $\begin{array}{l}\text { Total heating or cooling done in the } j \text { th temperature } \\
\text { bin, (Btu) }\end{array}$ \\
\hline$Q_{c y c}\left(T_{c y c}\right)$ & $\begin{array}{l}\text { Total heating or cooling during one "off"/"on" cycle at } \\
\mathrm{T}_{\text {cyc' (Btu) }}\end{array}$ \\
\hline$Q_{\text {def }}{ }^{(32)}$ & $\begin{array}{l}\text { Net heating during the frost accumulation and defrost } \\
\text { test, (Btu) }\end{array}$ \\
\hline$Q_{f}\left(T_{c y c}\right)$ & Total input fuel energy at $T_{c y c}$, (Btu) \\
\hline$Q_{f}(32)$ & $\begin{array}{l}\text { Total input fuel energy during the frost accumulation } \\
\text { and defrost test, (Btu) }\end{array}$ \\
\hline$Q_{f}\left(T_{j}\right)$ & Input fuel energy at temperature $T_{j},(B t u / h r)$ \\
\hline 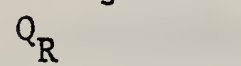 & Total resistance heat required during a season, (Btu) \\
\hline$R_{R}\left(T_{j}\right)$ & Total resistance heat in the $j$ th temperature bin, (Btu) \\
\hline$Q_{s s}\left(T_{j}\right)$ & $\begin{array}{l}\text { Steady-state heating or cooling capacity at temperature } \\
\mathrm{T}_{j} \text {, (Btu/hr) }\end{array}$ \\
\hline OC & Seasonal operating cost (\$) \\
\hline SPF & Seasonal performance factor \\
\hline$t$ & Time \\
\hline$T_{a 1}(t)$ & $\begin{array}{l}\text { Dry-bulb temperature of air entering the indoor side, } \\
\text { (F) }\end{array}$ \\
\hline$T_{a 2}(t)$ & Dry-bulb temperature of air leaving the indoor side, (F) \\
\hline $\mathrm{T}_{c}$ & $\begin{array}{l}\text { Change-over temperature (temperature corresponding to } \\
\text { zero heating and cooling requirements), (F) }\end{array}$ \\
\hline & $\begin{array}{l}\text { Outdoor dry-bulb temperatures at which cyclic tests are } \\
\text { conducted, (F) }\end{array}$ \\
\hline$T_{j}$ & Representative temperature for bin $j,(F)$ \\
\hline$T_{\text {off }}$ & $\begin{array}{l}\text { Outdoor temperature at which compressor is automatically } \\
\text { turned off (heating only) }\end{array}$ \\
\hline $\mathrm{T}_{\mathrm{H}}(\mathrm{t})$ & $\begin{array}{l}\text { The higher of the dry-bulb temperatures of the air } \\
\text { entering and leaving the indoor side }\end{array}$ \\
\hline$T_{L}(t)$ & $\begin{array}{l}\text { The lower of the dry-bulb temperatures of the air enter- } \\
\text { ing and leaving the- Indoor side } \\
\text { Indoor a Ir flow rate,(cfm) }\end{array}$ \\
\hline & Specific volume of air-water mixture, $\left(\mathrm{ft}^{3} / 1 \mathrm{bm}\right)$ \\
\hline & Humidity ratio, (Ibm water/1bm dry air) \\
\hline
\end{tabular}



$x\left(T_{j}\right)$
$z$
$\alpha^{i}$
$n_{s}$
$\psi^{i}$
Heating or cooling load factor at temperature $T_{j}$
Normalized speed at intermediate speed $\mathrm{N}^{1}$
Normalized part-speed capacity factor
Efficiency of producing supplemental heat from primary
fuel $\left(\eta_{s}=0.3\right.$ if electric resistance heat is used)
Normalized part-speed input energy factor

\section{Subscripts}

H

C

ss

cyc

j

Superscripts

0

i

1

2
Heating

Cooling

Steady-state

G.yclic

$\mathrm{T}$ emperature bin number

Low speed (smallest capacity)

Intermediate speed (intermediate capacity)

Hìh speed (greatest capacity)

Designates superseripts 0 and 1 
ABSTRACT

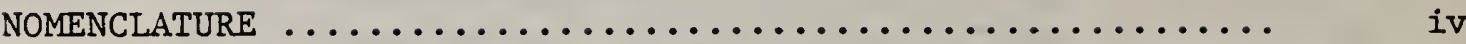

LIST OF TABLES AND FIGURES $\ldots \ldots \ldots \ldots \ldots \ldots \ldots \ldots \ldots \ldots \ldots \ldots \ldots \ldots \ldots \ldots$

1. INTRODUCTION $\ldots \ldots \ldots \ldots \ldots \ldots \ldots \ldots \ldots \ldots \ldots \ldots \ldots \ldots \ldots \ldots$

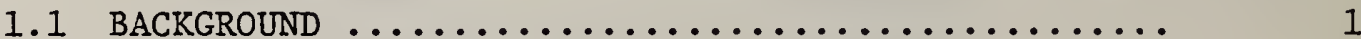



1.3 CLASSIFICATION OF ENGINE-DRIVEN HEAT PUMP SYSTEMS.

1.4 PERFORMANCE CONSIDERATIONS $\ldots \ldots \ldots \ldots \ldots \ldots \ldots \ldots \ldots$

2. RECOMMENDED TESTING REQUIREMENTS $\ldots \ldots \ldots \ldots \ldots \ldots \ldots \ldots \ldots$

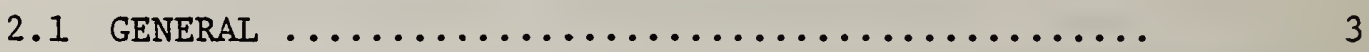

2.2 STEADY-STATE OPERATION $\ldots \ldots \ldots \ldots \ldots \ldots \ldots \ldots \ldots \ldots$

2.2.1 Single-Speed Operation ............... 5

2.2.2 Two-Speed/Dual-Capacity Operation ........

2.2.3 Continuously Variable-Speed Operation ..... 5

2.3 PART-LOAD (CYCLIC) OPERATION $\ldots \ldots \ldots \ldots \ldots \ldots \ldots \ldots$

2.4 FROST ACCUMULATION AND DEFROST OPERATION ........

2.5 INDOOR-SIDE AND OUTDOOR-SIDE AIR QUANTITY .......

3. RECOMMENDED TEST PROCEDURES ................. 8

3.1 INTRODUCTION ....................... 8



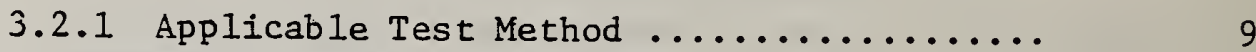

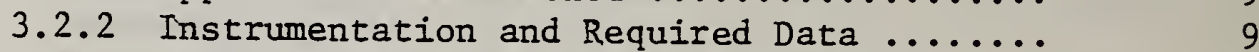

3.2.3 Test Operating Procedure and Results ...... 10

3.2 .4 Test Tolerances .................... 10

3.3 PART-LOAD (CYCLIC) TEST PROCEDURE ............ II

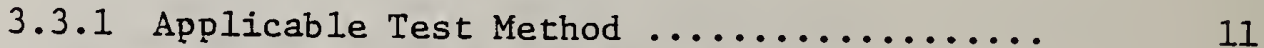

3.3.2 Instrumentation and Required Data........................... 11

3.3.3 Test Operating Procedure and Results ...... 11

3.3 .4 Test Tolerances .................... 12

3.4 FROST ACCUMULATION AND DEFROST TEST PROCEDURE ... 12

3.4.1 Applicable Test Method .............. 12 
TABLE OF CONTENTS (Continued)

$\underline{\text { Page }}$

3.4.2 Instrumentation and Required Data ........ 13

3.4.3 Test Operating Procedure and Results ...... 13

3.4 .4 Test Tolerances .................... 13

4. BUILDING LOADS AND CLIMATE SPECIFICATIONS ........... 14



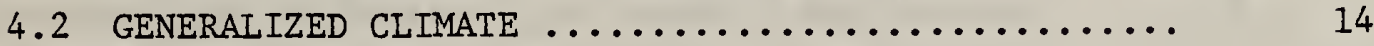

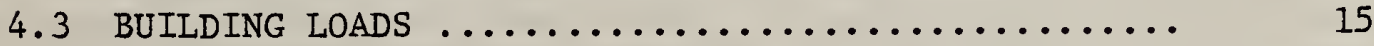

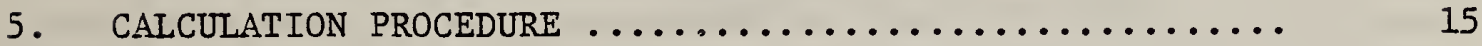

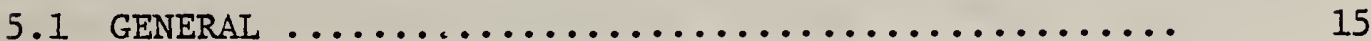





5.4 SEASONAL PERFORMANCE FACTOR AND SEASONAL OPERATING

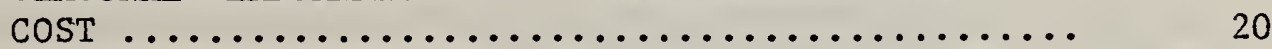

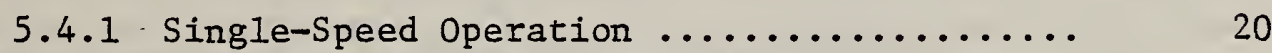

5.4.2 Two-Speed/Dua1-Capacity Operation ........ 30



5.5 FROST ACCUMULATION AND DEFROST CALCULATIONS $\ldots \ldots$.

6. RECOMMENDED RATING REQUIREMENTS ................ 28

7. LIMITATIONS OF THE RECOMMENDED TEST AND RATING PROCEDURES

References $\ldots \ldots \ldots \ldots \ldots \ldots \ldots \ldots \ldots \ldots \ldots \ldots \ldots \ldots \ldots \ldots \ldots \ldots$

Appendix A. Propagation of Measurement Uncertainties into the Steady-State Coefficient of Performance



A. I Introduction ..................... 45

A.2 Steady-State Heating Coefficient of

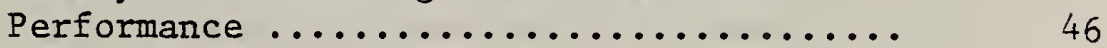

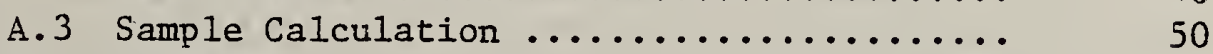

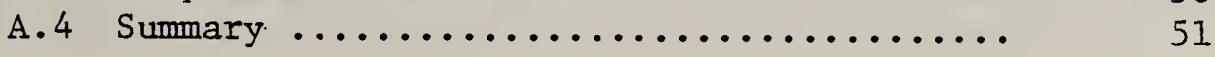


Page

Table

Title

1

2

3

4

5

6

7.

8

Figure

1

2

3.

Summary of Test Requirements $\ldots \ldots \ldots \ldots \ldots \ldots \ldots$

Test Operating and Test Condition Tolerances .....

Generalized Climates for Residential Applications •

Generalized Climates for Light Commercial/

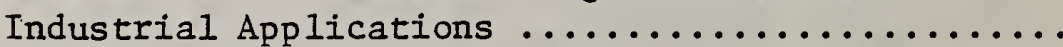

Summary Weather Data for Representative Climates ..

Calculation Sheet for Single-Speed Heat Pumps .....

Calculation Sheet for Two-Speed/Dual Capacity or

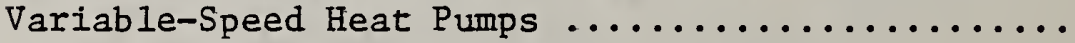

Test Requirements for Single-Speed Heat Pump

Systems

Test Requirements for Two-Speed (Dual Capacity)

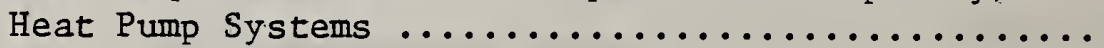

Test Requirements for Variable-Speed Heat Pump

Systems 


\subsection{BACKGROUND}

The application of a heat engine to a heat pump has the inherent advantages of engine waste heat recovery to supplement the refrigeration cycle heating mode output, and increased heat pump efficlency in both the heating and cooling modes due to capac1ty modulation. There are currently a number of innovative engine-driven heat pump development projects in progress around the country [ref. 1-5], and there is as yet no standardized test and evaluation procedure available for these systems. Therefore, industry and government are unable to evaluate and compare these new heat pumps, and to make sound decisions regarding which are worthy of further development. A standardized test and rating procedure, incorporating provisions specifically tallored to the nature of each heat pump system, is required so that the results of different research groups working on different types of engine-driven heat pump systems may be effectively compared on the same technical basis.

\subsection{OBJECTIVE AND SCOPE}

The objective of this study is the development of a generic test and rating procedure for engine-driven heat pump systems which are 11kely to be employed in residential and small commerclal buildings in the future. Inherent in the development of these procedures is the formulation of calculation procedures to estimate the seasonal performance and seasonal cost of operation of these systems. The test procedures and the rating and calculation procedures recommended herein apply only to prototype, heat engine-driven, air-to-air, mechanical compression, Rankine-cycle heat pumps operating in the heating and cooling modes. Since consideration is restricted to prototype systems, it is expected that the recommended test and rating procedures w111 be used by the Industry as a tool to evaluate and compare the performance of such systems, and may eventually provide a foundation for a future less burdensome test and rating standard for factory-made systems which reach the market place.

\subsection{CLASSIFICATION OF ENGINE-DRIVEN HEAT PUMP SYSTEMS}

Engine-driven heat pump systems are typically classified according to the thermodynamic power cycle of the prime mover and the thermodynamic cycle of the refrigerator. In addition, they are often classed according to the nature of their heat source and sink (air-to-air, liquid-toliquid, etc.). For residential and small commercial applications, an air heat source and sink is the most practical and common. Since current development efforts [1-5] involve air-to-air designs, the recommended test and rating procedures will be restricted to these heat pumps. 
of the many power cycles available for heat pump applications, the five most common are the Brayton, Diesel, Otto, Rankine, and Stirling cycles. The Brayton engine is normally rotary in design; the Rankine engine may be reciprocating or rotary, and the Otto, Diesel, and Stirling engines are all reciprocating, and they may be of a free-piston design. Since there is no reason to exclude any of these engines from consideration in: heat pump applications, the recommended test and rating procedures will be sufficiently general to include all of them. For purposes of generality, however, the prime mover will be conceptualized as a "black box" which converts input fuel energy (liquid, solid, or gaseous) into useful. work and recoverable and non-recoverable waste energy. References to a particular engine type will not normally be made except in those instances where uniqueness of design or operation requires $1 t$.

The refrigeration cycle most commonly employed for residential and small. commercial applications is the vapor compression Rankine cycle. Since all current development efforts are using this cycle, the test and rating procedures recommended in this study will be restricted to it. The procedures will be sufficiently general, however, to be applicable to conventional positive and variable displacement compressors, as well as high-speed centrifugal or free-piston types.

\subsection{PERFORMANCE CONSIDERATIONS}

The current requirements for testing and rating of electrically-driven unitary heat pump equipment are described in the Air Conditioning and Refrigeration Institute (ARI) Standard 240-76. Test methods used to evaluate this equipment are described in the American Society of Heating, Refrigerating and Air Conditioning Engineers (ASHRAE) Standard 37-69. For air-source heat pumps the current heating mode rating requirements are based upon two steady-state tests conducted at indoor dry-bulb and wet-bulb temperatures of $70^{\circ} \mathrm{F}\left(21.1^{\circ} \mathrm{C}\right)$ and $60^{\circ} \mathrm{F}\left(15.6^{\circ} \mathrm{C}\right)$, respectively. One test is conducted at outdoor dry-bulb and wet-bulb temperatures of $47^{\circ} \mathrm{F}\left(8.3^{\circ} \mathrm{C}\right)$ and $43^{\circ} \mathrm{F}\left(6.1^{\circ} \mathrm{C}\right)$, and the other is conducted at $17^{\circ} \mathrm{F}$ $\left(-8.3^{\circ} \mathrm{C}\right)$ and $15^{\circ} \mathrm{F}\left(-9.4^{\circ} \mathrm{C}\right)$, respectively. In the cooling mode, the rating requirements are based on one steady-state test conducted at indoor dry-bulb and wet-bulb temperatures of $80^{\circ} \mathrm{F}\left(26.7^{\circ} \mathrm{C}\right)$ and $67^{\circ} \mathrm{F}$ $\left(19.4^{\circ} \mathrm{C}\right)$, respectively, and an outdoor dry-bulb temperature of $95^{\circ} \mathrm{F}$ $\left(35^{\circ} \mathrm{C}\right)$. In addition, for units which reject condensate to the outdoor air stream, an outdoor wet-bulb temperature of $75^{\circ} \mathrm{F}\left(23.9^{\circ} \mathrm{C}\right)$ is required.

Knowledge of the steady-state performance of a heat pump system at the ARI rating points is useful for single point rating and compar ative purposes, regardless of the power source. Such knowledge is insufficlent, however, to assess the non-steady-state performance of the system, and is insuffictent to determine the seasonal performance of the system. Experimental investigations of electric heat pumps have indicated that the "on-off" cycling that these units must undergo to satisfy comfort requirements often has a significant effect on the performance of the units in both modes of operation. Because of the dynamic characteristics of the heat engine, it's expected that cycling will have an 
even greater effect on the performance of an engine-driven system. Experimental investigations of engine-driven heat pump systems have shown that heating and cooling capacity and input energy are generally nonlinear functions of outdoor dry-bulb temperature. This is particularly true in the heating mode where heat pump capacity is supplemented with recovered engine heat. Because of differences in engine brake thermal efficiency and heat recovery characteristics, as well as differences in heat pump efficiency, the effect of outdoor temperature must be considered in the test and rating procedures and in the seasonal performance determinations. Additional factors which affect instantaneous and seasonal performance are the climate in which the system operates, the building load classification, capacity modulation, and defrost requirements. All of these factors are addressed in the recommended test, rating, and calculation procedures which follow.

\section{RECOMMENDED TESTING REQUIREMENTS}

\subsection{GENERAL}

The recommended testing and rating requirements for engine-drtven heat pumps are classified basically according to whether the system has single-speed, two-speed, or varlable-speed capability, and whether it is operating in the heating or cooling mode. The test requirements generally consist of a serles of steady-state wet-coil (or no-frost) tests which provide data necessary to define the steady-state performance curve, combined with two or more cyclic (dynamic) tests to determine the part-load performance. For varlable speed systems the test requirements also include a provision for steady-state, intermediate speed tests to determine part-speed performance. The performance of the system under frost accumulation and subsequent defrost operation is characterized by a single test under high relative humidity conditions. The system is then rated in both operating modes based upon tts steady-state performance at the ARI standard rating points, its seasonal performance factor, and Its seasonal operating cost. A summary of the testing requirements is presented in table 1 and is illustrated in figures 1-3.

\subsection{STEADY-STATE OPERATION}

The steady-state, wet-coll (or no-frost) testing requirements are dependent on whether the heat pump system has single-speed, two-speed, or variable-speed capability. The respective requirements are discussed below.

\subsubsection{Single-Speed Operation}

A total of six steady-state, wet-coil (or no-frost) tests shall be conducted according to the test procedures specified in section 3.2 . Of this total, two wet-coil tests shall be conducted in the cooling mode and the remaining four in the heating mode.

In the wet-coil cooling mode tests, the air entering the indoor portion of the unit shall have a dry-bulb temperature of $80^{\circ} \mathrm{F}\left(26.7^{\circ} \mathrm{C}\right)$ and a 
wet-bulb temperature of $67^{\circ} \mathrm{F}\left(19.4^{\circ} \mathrm{C}\right)$. The dry-bulb temperature of the air surrounding and entering the outdoor portion of the unit shall be $95^{\circ} \mathrm{F}\left(35^{\circ} \mathrm{C}\right)$ in the first test, and $80^{\circ} \mathrm{F}\left(26.7^{\circ} \mathrm{C}\right)$ in the second. For those units which reject condensate to the outdoor air stream, the outdoor wet-bulb temperatures entering the outdoor unit shall be $75^{\circ} \mathrm{F}$ $\left(23.9^{\circ} \mathrm{C}\right)$ and $64^{\circ} \mathrm{F}\left(17.8^{\circ} \mathrm{C}\right)$, respectively. The outdoor dry-bulb and wetbulb temperatures of the first test point coincide with the ARI standard rating point for air-source units in the cooling mode. The $80^{\circ} \mathrm{F}\left(26.7^{\circ} \mathrm{C}\right)$ dry-bulb temperature of the second point was chosen because it approximates the average operating temperature in northern climates during the cooling season. The corresponding wet-bulb temperature was chosen so that the relative humidities of both testing points are approximately equal.

In the heating mode tests, the air entering the indoor portion of the unit shall have a dry-bulb temperature of $70^{\circ} \mathrm{F}\left(21.1^{\circ} \mathrm{C}\right)$ and a maximum wet-bulb temperature of $60^{\circ} \mathrm{F}\left(15.6^{\circ} \mathrm{C}\right)$. The four wet-coil (or no-frost) tests shall be conducted with the dry-bulb temperature of the air surrounding and entering the outdoor unit equal to $47^{\circ} \mathrm{F}\left(8.3^{\circ} \mathrm{C}\right), 32^{\circ} \mathrm{F}$ $\left(0^{\circ} \mathrm{C}\right), 17^{\circ} \mathrm{F}\left(-8.3^{\circ} \mathrm{C}\right)$, and $-13^{\circ} \mathrm{F}\left(-25^{\circ} \mathrm{C}\right)$, respectively. The corresponding wet-bulb temperatures of the entering air shall be $43^{\circ} \mathrm{F}\left(6.1^{\circ} \mathrm{C}\right)$, $30^{\circ} \mathrm{F}\left(-1.1^{\circ} \mathrm{C}\right)$ or less, and $15^{\circ} \mathrm{F}\left(-9.4^{\circ} \mathrm{C}\right)$, respectively, for the first three tests, and shall be left uncontrolled for the remaining one. The outdoor conditions of the first and third testing points coincide with the ARI standard high and low temperature rating points for air-source units in the heating mode. The second test point was chosen in order to provide a reference for a subsequent frost accumulation and defrost test, and the fourth point was chosen in order to establish low temperature system performance. The four testing points shall be used to determine the system performance as a function of outdoor dry-bulb temperature.

\subsubsection{Two-Speed/Dual-Capacity Operation}

In order to properly characterize the performance of engine-driven systems with two-speed compressor capability, the test requirements are separated into high-speed and low-speed requirements, and they shall be conducted according to the test procedures specified in section 3.2 . In the cooling mode, the steady-state tests for both compressor speeds are the same as those described in section 2.2.1 for single speed operation, and are the minimum tests necessary to estimate the steady-state performance curve for each speed. In the heating mode, however, three highspeed compressor tests are specified over a range of low ambient temperatures, and three low-speed compressor tests are spectfied over a range of higher ambient temperatures. This approach-reflects the way in which most two-speed systems are designed to operate, and also reduces the number of tests necessary to establish the performance curve for each compressor speed. 
The three wet-coil (or no-frost) low-speed tests shall be conducted with the dry-bulb temperature of the air surrounding and entering the outdoor unit equal to $47^{\circ} \mathrm{F}\left(8.3^{\circ} \mathrm{C}\right), 32^{\circ} \mathrm{F}\left(0^{\circ} \mathrm{C}\right)$ and $17^{\circ} \mathrm{F}\left(-8.3^{\circ} \mathrm{C}\right)$, respectively. The corresponding wet-bulb temperatures of the entering air shall be $43^{\circ} \mathrm{F}\left(6.1^{\circ} \mathrm{C}\right), 30^{\circ} \mathrm{F}\left(-1.1^{\circ} \mathrm{C}\right)$ and $15^{\circ} \mathrm{F}\left(-9.4^{\circ} \mathrm{C}\right)$. A maximum wet-bulb temperature of $30^{\circ} \mathrm{F}\left(-1.1^{\circ} \mathrm{C}\right)$ was chosen for the second test in order to reduce the accumulation of frost on the outdoor coil. Although frost may form during this test, and during the subsequent test at $17^{\circ} \mathrm{F}\left(-8.3^{\circ} \mathrm{C}\right)$ dry-bulb temperature, its effect during the time span of the tests is not expected to be great.

The three no-frost high-speed tests shall be conducted at dry-bulb temperatures of $17^{\circ} \mathrm{F}\left(-8.3^{\circ} \mathrm{C}\right), 2^{\circ} \mathrm{F}\left(-16.7^{\circ} \mathrm{C}\right)$, and $-13^{\circ} \mathrm{F}\left(-25.0^{\circ} \mathrm{C}\right)$. The wet-bulb temperature of the first point shall be $15^{\circ} \mathrm{F}\left(-9.4^{\circ} \mathrm{C}\right)$ and shall be left uncontrolled for the remaining two.

Systems which use twin compressors, staged compression, dual firing rates, suction/discharge valve control, etc., to achieve dual capacity performance are subject to the same test requirements as those systems with two-speed compressors. In these instances the term "high-speed" shall mean operation with both compressors, or at the greatest capacity level, and "low-speed" shall mean one compressor, or smallest capacity operation. As indicated in table 1 and illustrated in figure 2, a total of ten steady-state tests shall be conducted for systems with two-speed capability.

\subsubsection{Continuously Variable-Speed Operation}

Experimental investigations of engine-driven heat pump systems have shown that heating and cooling capacity, input fuel energy, and input electric energy are generally nonlinear functions of compressor speed as well as of each other. Therefore, for those systems whose speed is continuously variable, the test requirements and rating procedures must include provisions to estimate the system's performance at speeds intermediate to the maximum and minimum speed.

The steady-state test requirements for variable-speed heat pump systems are divided into two sets. The requirements for the first set are exactly the same as those described in section 2.2.2 for two-speed operation. High and low compressor speed shall then mean maximum and minimum compressor speed. As in section 2.2.2, a total of ten steadystate tests shall be conducted according to the test procedures specified in section 3.2 .

The second set of requirements consists of steady-state intermediate speed tests conducted at a normalized speed $Z$ according to the test procedures specified in section 3.2. The normalized speed $Z$ is defined as: 


$$
z=\frac{N^{i}-N^{0}}{N^{1}-N^{0}}
$$

where $Z$ varies from 0 to 1 , and $N^{0}, N^{1}$, and $N^{1}$ represent minimum speed, maximum speed, and any intermediate speed, respectively. One wet-coil intermediate speed test shall be conducted in the cooling mode. The indoor conditions shall be as specified in section 2.2 .1 , and the outdoor dry-bulb and wet-bulb temperatures shall be $80^{\circ} \mathrm{F}\left(26.7^{\circ} \mathrm{C}\right)$ and $64^{\circ} \mathrm{F}$ $\left(17.8^{\circ} \mathrm{C}\right)$, respectively. The test shall be conducted at a normalized speed of $Z=1 / 2$.

One no-frost intermediate speed test shall be conducted in the heating mode at the indoor conditions specified in section 2.2.1. The outdoor dry-bulb and wet-bulb temperatures shall be $17^{\circ} \mathrm{F}\left(-8.3^{\circ} \mathrm{C}\right)$ and $15^{\circ} \mathrm{F}$ $\left(-9.4^{\circ} \mathrm{C}\right)$, and the test shall be conducted at $\mathrm{Z}=1 / 2$. The above intermediate speed test requirements are summarized in table 1 and illustrated in figure 3. The results will be used to calculate part-speed capacity and input energy with the calculation procedure described in section 5.3 .

\subsection{PART-LOAD (CYCLIC) OPERATION}

Laboratory investigations (refs. 6 and 7) have shown that the heating and cooling performance of electric heat pumps is significantly reduced when operated under part-load, or cyclic, conditions. Performance degradation has been shown to be directly dependent on load and to be relatively insensitive to outdoor ambient conditions. During cyclic wet-coil cooling tests of electric heat pumps, it has been found that constant indoor conditions are difficult to maintain, and that dry-bulb and wet-bulb temperature measurement errors can create large uncertainties in the cyclic sensible and latent capacities. Further cooling tests have indicated, however, that cyclic wet-coil tests may be replaced by simpler and more accurate dry-coil tests. Specifically, the results showed that when steady-state and cyclic dry coil tests were conducted, the ratio of the cyclic COP to the steady-state COP was essentialiy the same as the COP ratio determined from wet-coil tests at the same cooling load factor.

The part-load test requirements during the cooling mode shall include one or more steady-state dry-coil tests and an equal number of cyclic dry-coil tests. These tests shall be performed in conjunction with each other according to the test procedures specified in sections 3.2 and 3.3 , respectively. The Indoor dry-buld temperature shall be $80^{\circ} \mathrm{F}$ $\left(26.7^{\circ} \mathrm{C}\right)$ and the wet-buld temperature shall be a value which does not cause condensate to form on the indoor coil. It is recommended that the temperature be equal to or less than $57^{\circ} \mathrm{F}\left(13.9^{\circ} \mathrm{C}\right)$. The outdoor drybulb-temperature shall be $80^{\circ} \mathrm{F}\left(26.7^{\circ} \mathrm{C}\right)$ and the wet-bulb temperature shall be unspecifted. For systems with single and continuously-variable speed capability, there shall be one steady-state dry-coil test and one cyclic dry-coil test. For vartable-speed systems both tests shall occur 
at the minimum speed since this is the speed at which cycling will normally occur under low load conditions. For systems with two-speed (two-capacity) capability there shall be two steady-state dry-coil tests and two cyclic dry-coil tests, for a total of four. Since the dynamic performance of an engine-driven system is a function of speed (capacity), a steady-state and cyclic test shall occur at each of the two speeds of operation, and they shall be performed in conjunction with each other.

The cyclic test requirements during the heating mode shall include one cyclic test for single-speed and continuously-varlable speed systems. The outdoor dry-bulb and wet-bulb conditions shall be $47^{\circ} \mathrm{F}\left(8.3^{\circ} \mathrm{C}\right)$ and $43^{\circ} \mathrm{F}\left(6.1^{\circ} \mathrm{C}\right)$, respectively. Two cyclic tests shall be conducted for two-speed (dual-capacity) systams, one at each compressor speed. The low-speed test shall occur at the dry-bulb and wet-bulb conditions specified above, and the high-speed test shall occur at dry-bulb and wet-bulb conditions of $17^{\circ} \mathrm{F}\left(-8.3^{\circ} \mathrm{C}\right)$ and $15^{\circ} \mathrm{F}\left(-9.4^{\circ} \mathrm{C}\right)$, respectively. The indoor dry-bulb and wet-bulb temperatures shall be $70^{\circ} \mathrm{F}\left(21.1^{\circ} \mathrm{C}\right)$ and $60^{\circ} \mathrm{F}\left(15.6^{\circ} \mathrm{C}\right)$, respectively, for all cyclic heating tests.

The conditions specified for these cyclic heating tests are the same as those outlined in section 2.2.1 for two of the steady-state tests. Each cyclic heating test shall, therefore, be performed in conjunction with its corresponding steady-state test according to the procedures specified in section 3.2. The cyclic test requirements for heating and cooling are summarized in table 1 and figures $1-3$. The results will be used to calculate a part-load degradation coefficient $C_{D}$ with the calculation procedures described in section 5.2 .

\subsection{FROST ACCUMULATION AND DEFROST OPERATION}

Accumulation of frost on the outdoor coil has been shown (ref. 7) to cause a significant drop in the performance of electric heat pumps compared to their non-frosted performance. Since frost formation occurs most rapidly over a range of outdoor conditions in which most space heating systems accumulate many years of yearly operation, a frost accumulation and defrost test should be included in the test and rating procedures for engine-driven heat pump systems.

One proposed approach to account for the deteriorating effects of frost would be to apply a correction factor to all steady-state performance data obtained within the frost range. The correction would be a function of outdoor dry-bulb temperature and relative humidity, and would be based upon a sertes of frost accumulation tests. Because of the current lack of experimental data regarding the performance of engine-driven heat pump systems under frosted-coil and defrost conditions, it is very uncertain how such a correction should vary as a function of ambient temperature and humidity conditions. It is equally uncertain at this time as to what minimum tests should be required of the system developer in order to define these functions. Therefore, this approach is not recommended for the prototype systems addressed in these procedures. 
Instead, a single-point frost accumulation and defrost test is specified for frost rating purposes. As actual operating data become available under frosting conditions, the development of a more general frost correction should be investigated.

A single-point frost accumulation and defrost test shall be performed with the dry-bulb and wet-bulb temperatures of the air entering the outdoor unit equal to $32^{\circ} \mathrm{F}\left(0^{\circ} \mathrm{C}\right)$ and $30^{\circ} \mathrm{F}\left(-1.1^{\circ} \mathrm{C}\right)$, respectively. These conditions correspond to a relative humidity of $80 \%$. This is an average value for most regions of the country which have a significant number of their heating hours occurring at outdoor temperatures less than $35^{\circ} \mathrm{F}$ $\left(1.7^{\circ} \mathrm{C}\right)$. The indoor conditions shal1 be $70^{\circ} \mathrm{F}\left(21.1^{\circ} \mathrm{C}\right)$ dry-bulb and $60^{\circ} \mathrm{F}$ $\left(15.6^{\circ} \mathrm{C}\right)$ maximum wet-bulb temperature. For systems with two-speed (dual-capacity) or continuously-variable speed capability, the test shall occur at the lower speed (capactty) since most engine-driven systems would normally operate at this speed when the outdoor temperature is $32^{\circ} \mathrm{F}\left(0^{\circ} \mathrm{C}\right)$. The test shall be pseudo steady-state over a complete frost accumulation and defrost cycle, and it shall begin at defrost termination and continue until the next defrost termination. The time-until-defrost, the method of defrost, and the operating procedures during the defrost pertod shall not be specified. In this way, no single heat pump developer or type of engine-driven system w1ll be favored. The frost accumulation test shall be conducted according to the test procedures specified in section 3.4, and the results are to be reported in connection with the corresponding non-frosting steady-state test at $32^{\circ} \mathrm{F}\left(0^{\circ} \mathrm{C}\right)$ spectfied in section 2.2.1. The calculation procedure is described in section 5.5.

\subsection{INDOOR-SIDE AND OUTDOOR-SIDE AIR QUANTITY}

All steady-state and cyclic heating and cooling tests shall be conducted at the outdoor-side air quantity requirements spectfied in section 5.1.4.4 of ARI Standard 240-76 and ARI Standard 210-74, respectively. AII steady-state and cyclic heating and cooling tests shall be conducted at the indoor-side air quantity specified in section 5.1.4.3 of ARI Standard 240-76 and ARI Standard 210-74, respectively. Rated heating and cooling capacity shall refer to the capacity of the system as measured at the highest speed at an outdoor dry-bulb temperature of $47^{\circ} \mathrm{F}\left(8.3^{\circ} \mathrm{C}\right)$ and $95^{\circ} \mathrm{F}\left(35^{\circ} \mathrm{C}\right)$, respectively.

\section{RECOMMENDED TEST PROCEDURES}

\subsection{INTRODUCTION}

The recommended test procedures have been divided into steady-state procedures, part-load (cyclic) procedures, and frost accumulation and defrost test procedures. They have been established within the general framework of providing adequate and reliable test data on the performance of prototype heat pump systems at a reasonable investment of funds, time, and effort by the developer. Where feastble, the steadystate test procedures have been adapted from the ASHRAE Standard 37-69, 
and the part-load procedures have been adapted from references 6 and 7 . As additional performance data and operating experience are acquired on engine-driven systems, additions or modifications to these procedures may be required.

\subsection{STEADY-STATE TEST PROCEDURE}

The following test procedures pertain to the steady-state heating and cooling tests specifled in section 2.2 and illustrated in table 1 and figures $1-3$.

\subsubsection{Applicable Test Method}

ASHRAE Standard 37-69 describes the following four test methods that may be used to determine the heating and cooling capacities of unitary electric heat pump equipment:
a) Air-Enthalpy Method - Indoor Side
b) Air-Enthalpy Method - Outdoor Side
c) Compressor Calibration Method
d) Volatile Refrigerant Flow Method.

Because of differences in engine-driven heat pump types and differences in heat recovery equipment configuration, the test method most applicable to all equipment types is the Alr-Enthalpy Method - Indoor Side. Therefore, all steady-state heating and cooling tests on engine-driven heat pump equipment shall employ this method as the required test method. Prototype developers are encouraged, however, to simultaneously employ additional measurement and analysis techniques as a check on the overall experimental system. Performance calculations should be based, however, only on the results of the Indoor Side Air-Enthalpy Method. Test room requirements are the same as those specified in section 11.1 of the ASHRAE Standard 37-69.

\subsubsection{Instrumentation and Required Data}

The steady-state performance tests shall have the same instrumentation and data requirements as those specified in section 10 and table II of ASHRAE Standard 37-69, with the following additions or modifications:

(a) Iiquid or gaseous fuel quantity shall be measured with a suitable integrating type meter having an accuracy within $\pm 2.0 \%$ of the quantity measured.

(b) The lower heating value (LHV) of a representative sample of fuel shall be determined by suitable chemical or calorimetric analysis and shall be used in all subsequent input fuel energy calculations.

(c) The dry-bulb temperature of the atr entering and leaving the Indoor side (or the difference between these two temperatures), and the dry-bulb temperature of the air entering; 
the outdoor refrigerant coll shall be continuously recorded with instrumentation having a total system accuracy and precision within $\pm 1.0^{\circ} \mathrm{F}\left(0.6^{\circ} \mathrm{C}\right)$.

(d) The electric energy usage of all components and accessorles (fans, pumps, blowers, control clrcults, etc.) shall be measured with watt-hour meters that are accurate to within $\pm 2.0 \%$ of the quantity measured.

\subsubsection{Test Operating Procedure and Results}

The engine-driven heat pump system and any assoclated test room recond1tioning equipment shall be operated for at least one-half $(1 / 2)$ hour under equilibrium conditions before any steady-state heating or cooling performance data are recorded. Data shall then be recorded at tenminute intervals until four consecutive sets of readings within the tolerances specified in table 2 have been attalned.

Under some conditions of heating, a small amount of frost may accumulate on the outdoor coll, and a distinction needs to be made between frosting and non-frosting operation during the test perfod. For purposes of these procedures, the test is considered non-frosting provided that the dry-bulb temperature of the atr leaving the indoor and outdoor units does not deviate by more than $2.0^{\circ} \mathrm{F}\left(1.1^{\circ} \mathrm{C}\right)$ during the test. When this tolerance is exceeded because of frost, the defrost cycle shall be initiated manually and the steady-state test repeated. For those systems with controls which periodically initiate a defrost cycle based upon time, the control system shall be modified to prevent defrost during the steady-state heating tests.

The steady-state heating and cooling results shall include each of the following quantities calculated using the procedures described in section 5.1:

(a) Total heating or cooling capacity, Btu/hr (J/sec).

(b) Input fuel energy, Btu/hr (J/sec).

(c) Total electric power input to all components and accessorles, watts.

(d) Steady-state Coefficient of Performance.

Sections 12.1.5-12.1.7 of the ASHRAE Standard 37-69 shall apply for all steady-state heating and cooling test results.

\subsubsection{Test Tolerances}

All steady-state heating and cooling tests shall be conducted within the applicable test operating and test condition tolerances specified in table 2. Test operating tolerance is defined as the greatest permissible difference between maximum and minimum instrument observations during the test. Test condition tolerance is defined as the maximum permissible variation of the average of the test observations from the desired test condition. Variations greater than those prescribed in table 2 shall invalidate the test. 


\subsection{PART-LOAD (CYCLIC) TEST PROCEDURE}

The following test procedures pertain to the cyclic dry-coil and nonfrosting tests specified in section 2.3 and illustrated in table 1 and figures $1-3$.

\subsubsection{Applicable Test Method}

All part-load (cyclic) tests shall employ only the A1r-Enthalpy Method Indoor Side, and each test shall be performed in conjunction with its corresponding steady-state test as described in section 2.3 .

\subsubsection{Instrumentation and Required Data}

The instrumentation and data requirements for the cyclic test shall be the same as those specified in section 3.2 .2 for steady-state tests. An additional requirement is that the instrumentation used to measure the air temperature entering and leaving the indoor side, or the difference between these two temperatures, shall have a response time of 2.5 seconds or less. Response time is defined as the time required for the instrumentation to attain $63 \%$ of the final steady-state temperature difference when subjected to a step change of $15^{\circ} \mathrm{F}\left(-9.4^{\circ} \mathrm{C}\right)$ or more.

\subsubsection{Test Operating Procedure and Results}

Each cyclic test shall immediately follow the corresponding steady-state test described in section 2.3 and illustrated in table 1 . At the conclusion of the steady-state test the engine-driven heat pump system shall be manually cycled "off" and "on" until steadily repeating ambient conditions are achieved in both the indoor and outdoor test chambers, but for not less than two complete "off"/"on" cycles. Without disrupting the cycling process, the system shall then be operated for an additional "off"/"on" cycle during which the required test data shall be taken. During this test cycle the indoor and outdoor conditions shall remain within the tolerances specified in tabie 2 .

A complete "off"/"on" cycle shall be defined as an "off" pertod of 24 minutes and an "on" period of six minutes. This results in a cycling rate of two cycles per hour which is approximately the rate at which thermostats are set in order to maintain building temperature variations within $3^{\circ} \mathrm{F}\left(1.7^{\circ} \mathrm{C}\right)$ when operating under a $20 \%$ heating or cooling load.

For those engine-driven systems which permit the compressor to be quickly disengaged from the prime-mover, cycling "off" and "on" shall refer to the refrigerant compressor operation. For those systems whose refrigerant compressor is permanently coupled to the prime-mover, cycling "off" and "on" shall refer to the inttiation of that action which results in the most rapid stopping and starting of the refrigerant compressor, respectively. Depending on the type of engine, this may require decreasing or stopping the fuel flow to the engine, stopping or 
diverting the working fluld from the engine's expander, equalizing pressures across the expander, etc. The indoor fan shall cycle "off" and "on" with the compressor, but its cycling times may be delayed or modified by controls which are normally installed with the system. Operation and control of the engine and associated components during the "off" and "on" periods shall be determined by the manufacturer. Any fuel consumed by the engine and any electric power used by pumps, fans, blowers, controls, etc., during the "off" perlod shall be measured, however, and included with "on" perfod energy in subsequent performance calculations. Also, provistons should be made to measure and include any "coast-down" heating or cooling which may occur after action has been initiated to stop the refrigerant compressor. If, during the cyclic heating tests, the engine continues to operate during the "off" period, the recovered engine waste energy shall be measured and Included with "on" period energy.

The cyclic test results shall include the following quantities calculated for the complete test cycle using the procedures described in section 5.2:

(a) Total heating or cooling capacity over the test cycle, Btu $(J)$.

(b) Total input fuel energy over the test cycle, Btu (J).

(c) Total electric power input to all components and accessories over the test cycle, kWh.

(d) Cyclic Coefficient of Performance.

The steady-state and cyclic test results shall be used to calculate a part-load degradation coefficlent $C_{D}$ according to the calculation procedures outlined in section 5.2 .

\subsubsection{Test Tolerances}

The cyclic heating and cooling tests shall be conducted within the test operating and test condition tolerances specified in table 2 . In order to meet the required air temperature tolerances, it is recommended that electric resistance heaters be installed in the indoor and outdoor chambers to offset the fluctuating heating and cooling loads imposed by the cycling equipment.

\subsection{FROST ACCUMULATION AND DEFROST TEST PROCEDURE}

The following test procedures pertain to the single-point frost accumulation and defrost test specified in section 2.4. The results of the test w111 be combined with the results of a steady-state non-frosting test, performed under the same ambient conditions, to form a single-point frost degradation coefficient $C_{\text {def }}$ according to the procedures outlined in section 5.5 .

\subsubsection{Applicable Test Method}

The frost accumulation and defrost test shall be conducted using the Air-Enthalpy Method - Indoor stde. 


\subsubsection{Instrumentation and Required Data}

The instrumentation and data requirements shall be the same as those specified in section 3.2.2 for steady-state tests. They shall also include the 2.5-second response requirement for temperature instrumentation specified in section 3.3 .2 for cyclic tests.

\subsubsection{Test Operating Procedure and Results}

The engine-driven heat pump system shall be operated for at least onehalf (1/2) hour under equilibrium ambient conditions prior to the actual test. Then, in order to assure that the outdoor refrigerant coil is frost-free at the start of the test, the system shall be operated through a manually induced but normally terminated defrost period. The test shall then commence at defrost termination and shall continue through the frost accumulation and subsequent defrost periods. It shall terminate at defrost termination. Defrost initiation and termination shall be governed by the normal controls associated with the system. Data shall be taken at ten-minute intervals during the frost accumulation heating period, and the times at defrost initiation and termination shall be recorded. Since defrost method, control, and mode of operation will generally be dependent upon specific equipment configuration and engine type, they shall be determined by the manufacturer and shall not be part of these test procedures. However, the total fuel consumed by the engine, the total electric power used by associated components (excluding resistance heaters which may be installed), and the total heating and cooling done during the defrost period shall be measured and included in the overall performance calculations.

The test results shall include the following quantities calculated for the frost accumulation and defrost cycle (defrost termination to defrost termination) using the procedures described in section 5.5

(a) Net heating capacity, Btu (J)

(b) Total input fuel energy, Btu (J)

(c) Total electric power input, kWh

(d) Frosting-defrost Coeffictent of Performance

These results shall be combined with the results of the steady-state non-frosting test to determine a frost degradation coefficient $C_{\text {def }}$ using the procedures outlined in section 5.5 .

\subsubsection{Test Tolerances}

The test operating and test condition tolerances which must be maintained during the frost accumulation and defrost test are specified in table 2 . The indoor and outdoor conditions shall be based only on the values occurring during the heating period. 


\subsection{INTRODUCTION}

The seasonal performance and seasonal cost of operation of any heat pump system depends not only upon the instantaneous performance of the system under specific indoor and outdoor condltions, but also upon the type of building in which it's installed and its thermal load, and the climate in which the building is situated. Because of the wide range of heating and cooling climates in the United States, and the even wider range of bullding types and thermal requirements, it becomes impossible to adequately characterize the performance of a heat pump system for all regions of the country with one or two seasonal indicators. Because of waste heat recovery, however, engine-driven heat pump systems are most applicable to northern climates where the energy requirements are predominantly heating and the engine's recovered waste heat can be effectively utilized. There will be applicatlons, however, in which the system is located in a southern climate. In these instances, the cooling requirements may be approximately equal to, or even greater than, the heating requirements. In order to provide the prototype developer some latitude and flexibility in establishing the seasonal performance of his product, the following evaluation approach is recommended for seasonal calculations:

(a) assume a generalized northern climate and a generalized southern climate in which an engine-driven heat pump system is most likely to be located.

(b) for each climate, assume representative heating and cooling design temperatures at which the system heating and cooling capacities equal the butlding energy requirements.

(c) assume heating and cooling loads typtcal of a residential Building, and of a light commercial/industrial bullding.

(d) for both seasons, use the temperature bin method to determine the seasonal performance factor and the seasonal operating cost based upon the appropriate bullding type and the cholce of one of the two generalized climates.

While this seasonal rating approach suffers the inevitable disadvantages associated with climate and building generalization, it does provide a sultable technique for assessing the relative seasonal performance of different heat pump systems which are designed for the same market and the same general climate.

\subsection{GENERALIZED CLIMATE}

Tables 3 and 4 list temperature bin information and the fractional hours in each bin during the heating and cooling season for the generalized northern and southern climates. The tables are based upon residential and commercial/Industrial applications, respectively. The fractional hours in each bin for northern climate were determined by averaging weather data from six U.S. cities, and the fractional hours for the 
southern climate were obtained by averaging data from eight cities. Table 5 lists average heating degree days DD, heating design temperature $\mathrm{HDT}$, and total bin hours in heating $\mathrm{BHH}$, and cooling $\mathrm{BHC}$, for each climate. The cooling design temperature is $95^{\circ} \mathrm{F}\left(35^{\circ} \mathrm{C}\right)$ for both climates.

\subsection{BUILDING LOADS}

Heating and cooling requirements are determined for residential applications and for light commercial/industrial applications by assuming a linear relationship between building load and outdoor temperature. The heating and cooling load lines extend from zero load at a specified change-over temperature $T$, to values which equal the steady-state heating and cooling capacities at assumed outdoor design temperatures of HDT and $95^{\circ} \mathrm{F}\left(35^{\circ} \mathrm{C}\right)$, respectively. The building load-temperature relationship is given by:

$$
\begin{aligned}
& B L\left(T_{j}\right)=\frac{\dot{Q}_{s S}(\text { HDT })[5 j-2]}{T_{c}+5} T_{j}<T_{c} \\
& B L\left(T_{j}\right)=\frac{\dot{Q}_{S S}(95)[5 j-3]}{95-T_{c}} T_{j}>T_{c}
\end{aligned}
$$

where $j=1,2,3, \ldots, n . \dot{Q}_{s s}(\mathrm{HDT})$ and $\dot{Q}_{\mathrm{s}}$ (95) are the measured steadystate heating and cooling cấpacities of thes system at the assumed design temperatures, and $n$ represents the total number of non-zero temperature bins. $T_{j}$ is the representative temperature of the $j$ th $b i n$ and is given
by:

$$
\begin{array}{ll}
T_{j}=T_{c}+2-5 j, & T_{j}<T_{c} \\
T_{j}=T_{c}-3+5 j, & T_{j}>T_{c}
\end{array}
$$

The change-over temperature $\mathrm{T}$, for residential applications is assumed to be $65^{\circ} \mathrm{F}\left(18.3^{\circ} \mathrm{C}\right)$. For light commercial/industrial applications, Ic was determined to be $55^{\circ} \mathrm{F}\left(12.8^{\circ} \mathrm{C}\right)$. This results from assuming a constant building internal load $\dot{Q}_{i}$ equal to one-third of the building shell cooling load at $95^{\circ} \mathrm{F}\left(35^{\circ} \mathrm{C}\right)$, or equivalently: $\dot{Q}_{i}=\mathrm{BL}(95) / 4$. The residential heating and cooling load lines are illustrated in figures $1-3$.

\section{CALCULATION PROCEDURE}

\subsection{GENERAL}

The steady-state heating and cooling capacity $\dot{Q}_{S S}\left(T_{j}\right)$ at each test point shall be calculated using the appropriate equations specified in section 3.7 of the ASHRAE Standard 37-69. For heat pump systems which may not have indoor-air circulating fans furnished as part of the system, their measured heating and cooling capacities shall be adjusted by 
adding $_{3}$ or subtracting, respectively, $1250 \mathrm{Btu} / \mathrm{hr}$ per 1000 SCFM (0.78 watts per $\mathrm{dm} / \mathrm{s}$ ) of indoor air flow to or from the measured values. Similarly, 366 watts of electrical energy per 1000 SCFM shall be added to the total measured steady-state electrical power input $\dot{\mathrm{E}}_{\mathrm{SS}}\left(\mathrm{T}_{j}\right)$.

The input fuel energy rate $\dot{Q}_{f}\left(T_{j}\right)$ under steady-state conditions at bin temperature $T_{j}$ shall be determined from:

$$
\dot{Q}_{f}\left(T_{j}\right)=\dot{m}_{f}\left(T_{j}\right) \cdot(L H V)
$$

where $m_{f}\left(T_{j}\right)$ is the fuel mass (or volume) flow rate at temperature $T_{j}$ and is determined from the fuel quantity measured over the specified ${ }^{j}$ test period. LHV is the lower heating value of the fuel expressed on a mass (or volume) basis.

The steady-state coefficient of performance COP ( $T_{j}$ ) of an enginedriven heat pump system based upon source energys shal1 be determined from:

$$
\operatorname{COP}_{s s}\left(T_{j}\right)=\frac{\dot{Q}_{s S}\left(T_{j}\right)}{\dot{Q}_{f}\left(T_{j}\right)+3.413\left[\frac{\dot{E}_{S S}\left(T_{j}\right)}{0.3}\right]}
$$

Where $\dot{\mathrm{E}}_{S S}\left(\mathrm{~T}_{j}\right)$ is the steady-state electrical power input at temperature $\mathrm{T}_{j}, 3.413$ converts watts to $\mathrm{Btu} / \mathrm{hr}$, and the factor 0.3 is an approximation for the efficiency of electric power generation and transmission.

The steady-state capacity, input electric power, and input fuel energy at bin temperatures other than the test points shall be determined through linear interpolation of data from the test points immediately adjacent (above and below) to the bin temperature in question. In those instances where the bin temperature is either greater than or less than all the test points, the data shall be linearly extrapolated from the two closest points. For residential heating applications, table 3 indicates that steady-state tests are conducted at bin temperatures $T_{j}$ where $j=4,7,10,13,16$. For commercial/industrial applications, table 4 indicates heating tests are conducted at bin temperatures $T_{j}$
where $j=2,5,8,11,14$.

\subsection{PART-LOAD (CYCLIC) PERFORMANCE}

In order to determine the seasonal performance of engine-driven heat pump equipment, several part-load parameters must first be defined or developed. A heating or cooling load factor $\mathrm{X}\left(\mathrm{T}_{j}\right)$ is defined by: 


$$
X\left(T_{j}\right)=\left\{\begin{array}{lll}
0 & ; & T_{j}<T_{\text {off }} \\
\hline B L\left(T_{j}\right) & B L\left(T_{j}\right)<\dot{Q}_{S S}\left(T_{j}\right) \\
\dot{Q}_{S S}\left(T_{j}\right) & ; & B L\left(T_{j}\right)>\dot{Q}_{S S}\left(T_{j}\right)
\end{array}\right.
$$

where $T_{\text {ff }}$ is the outdoor temperature at which the compressor is automatically turned off during the heating season (if applicable).

The results of the cyclic and steady-state heating and cooling tests shall be used in the following equations to calculate (a) Total heating or cooling during one "off"/"on" cycle $Q_{\text {( }}\left(T_{\text {, }}\right)$, (b) cyclic coefficient of performance for the test cycle $\mathcal{E \delta} \oint_{\text {cyf }}$ ), (c) cyclic degradation coefficient $C_{D}$, and (d) a part-load fyctor $\left.f_{L F}\left[X_{(T}\right)\right]$ at bin temperature $T_{j} \cdot T$ denotes the dry-bulb temperature at ${ }^{j}$ which cycling tests are conductedy $\left(80^{\circ} \mathrm{F}\right.$ and $\left.47^{\circ} \mathrm{F}\right)$.

$$
Q_{c y c}\left(T_{c y c}\right)=\frac{60 \dot{V} c_{p a} \Gamma}{v_{n}^{\prime}} \frac{\Gamma}{\left[1+w_{n}\right]}
$$

(time indoor-fan goes off)

where $\Gamma=\int\left[T_{H}(t) T_{L}(t)\right] d t$

$$
\text { (time indoor fan goes on) }
$$

and $\dot{V}, c_{p a}, v_{n}^{\prime}, W_{n}, T_{H}(t)$, and $T_{L}(t)$ are defined in the nomenclature.

$$
\operatorname{COP}_{c y c}\left(T_{c y c}\right)=\frac{Q_{c y c}\left(T_{c y c}\right)}{Q_{f}\left(T_{c y c}\right)+3.413\left[\frac{E_{c y c}\left(T_{c y c}\right)}{0.3}\right]}
$$

where $Q_{f}\left(T_{c y c}\right)$ is the total input fuel energy during the complete 30 minute Eestycycle. It is based upon the mass (or volume) of fuel consumed and the fuel's LHV. $E\left(T, T_{\text {. }}\right.$ ) is the total input electric energy measured during the test cycleyc For those heat pump systems which may not have indoor-air circulating fans, the calculated heating or cooling, and the measured input electric energy during one cycle shall be adjusted for the effect of a fan. The correction procedure shall be the same as that described in section 5.1 for steady-state 
tests, except that the correction shall equal the total energy transferred during the time of fan operation instead of a fixed energy rate.

Heating and cooling tests of electric heat pumps have indicated (refs. 6 and 7) that the cyclic-to-steady-state $\mathrm{COP}$ ratio $\left[\mathrm{COP} \mathrm{cyc}_{\mathrm{j}}\left(\mathrm{T}_{j}\right) /\left(\mathrm{COP} \mathrm{C}_{j}\right)\right]$ at any temperature $\mathrm{T}_{j}$ decreases approximately linearly as the load factor $\mathrm{X}\left(\mathrm{T}_{\mathrm{j}}\right)$ decreases. Assuming a similar variation for engine-driven heat pumps, a part-load degradation coefficient $C_{D}$ shall be calculated as follows:

$$
C_{D}=\frac{1-\left[\frac{{ }_{c y c}\left(T_{c y c}\right)}{\mathrm{COP}_{s s}\left(\mathrm{~T}_{c y c}\right)}\right]}{1-\left[\frac{\mathrm{Q}_{\mathrm{cyc}}\left(\mathrm{T}_{c y c}\right)}{0.5 \mathrm{Q}_{\mathrm{ss}}\left(\mathrm{T}_{c y c}\right)}\right]}
$$

where $0.5 \dot{Q}_{\text {Ss }}\left(T_{\text {fyc }}\right)$ is the total heating or cooling which would occur during the 0.5 four test cycle if steady-state conditions existed. $C_{D}$ is determined from the results of the steady-state and cyclic heating ${ }^{D}$ and cooling tests specified in section 2.3, and it is equal to one minus the zero-load factor intercept of the cyclic-to-steady-state COP ratio $\left[I-\operatorname{COP}\left(\mathrm{T}_{j}\right) / \mathrm{COP}\left(\mathrm{T}_{j}\right)\right.$ at $\left.\mathrm{X}\left(\mathrm{T}_{i}\right)=0\right]$, Laboratory tests of electric heat pumps [ref. ${ }^{S}$ ] have shown that $C_{D}$ is constant over a wide range of load factors $\left[X\left(T_{j}\right)\right]$, and is relatively independent of outdoor temperature. Denoting $\mathrm{COP}^{j} \mathrm{Cyc}\left(\mathrm{T}_{j}\right) / \mathrm{COP}{ }_{\mathrm{Ss}}\left(\mathrm{T}_{j}\right)$ as a heating or cooling partload factor PLF[X(T $\left.\left.\mathrm{T}_{j}\right)\right]$, then $\mathrm{C}_{\mathrm{D}} \mathrm{j}_{\text {and }} \mathrm{the}$ linear relationship between PLF $\left(\mathrm{X}\left(\mathrm{T}_{j}\right)\right)$ and $\mathrm{X}\left(\mathrm{T}_{j}\right)$ may be used to express PLF $\left(\mathrm{X}\left(\mathrm{T}_{j}\right)\right.$ ) $)$ as follows:

$$
\operatorname{PLF}\left(X\left(T_{j}\right)\right)=\frac{\operatorname{COP}_{C y c}\left(T_{j}\right)}{\operatorname{COP}_{s s}\left(T_{j}\right)}=1-C_{D}\left[1-X\left(T_{j}\right)\right]
$$

This expression shall be used to determine the heating or cooling cyclic coefficient of performance $\operatorname{COP}_{\text {cyc }}\left(\mathrm{T}_{j}\right)$ at any temperature $\mathrm{T}_{j}$.

\subsection{PART-SPEED PERFORMANCE}

The capacity, input electric energy, and input fuel energy of enginedriven heat pump systems are generally nonlinear functions of compressor speed as well as one another. The performance of variable-speed heat pumps at compressor speeds intermediate to the maximum and minimum speed shall be determined through the use of a normalized part-speed input energy factor $\psi^{I}$. When the total input fuel and electric energy at 
temperature $T_{j}$ is denoted by $E_{T}^{i}\left(T_{j}\right)$, where superscript $i$ designates intermediate speed $(Z=i)$, then $E_{T}{ }_{T}\left(T_{j}\right)$ may be determined from

$$
E_{T}^{i}\left(T_{j}\right)=E_{T}^{0}\left(T_{j}\right)+\psi^{i}\left[E_{T}^{1}\left(T_{j}\right)-E_{T}^{0}\left(T_{j}\right)\right]
$$

The superscripts 0 and 1 denote values. at minimum speed $(Z=0)$ and maximum speed $(Z=1)$, respectively. $\psi^{1}$ shall be determined from:

$$
\begin{aligned}
& \psi^{i}=\left[\frac{\psi^{1 / 2}}{\alpha^{1 / 2}}\right] \alpha^{i} ; 0<\alpha^{i}<\alpha^{1 / 2} \\
& \psi^{i}=\psi^{1 / 2}+\left[\frac{1-\psi^{1 / 2}}{1-\alpha^{1 / 2}}\right]\left(\alpha^{i}-\alpha^{1 / 2}\right) ; \alpha^{1 / 2}<\alpha^{i}<1
\end{aligned}
$$

where $\alpha^{i}$ is a normalized part-speed capacity factor defined at temperature $T_{j}$ by:

$$
\alpha^{i}=\frac{B L\left(T_{j}\right)-\dot{Q}_{s S}^{0}\left(T_{j}\right)}{Q_{s S}^{1}\left(T_{j}\right)-\dot{Q}_{s S}^{0}\left(T_{j}\right)}
$$

The values of $\psi^{1 / 2}$ and $\alpha^{1 / 2}$ required in equation (5.9) are determined for both operating modes from equations (5.8 and 5.10$)$, respectively. Their evaluation is based upon intermediate speed tests at $Z=1 / 2$ specified in section 2.2 .3 and conducted at outdoor-dry-bulb temperatures of $80^{\circ} \mathrm{F}\left(26.7^{\circ} \mathrm{C}\right)$ and $17^{\circ} \mathrm{F}\left(-8.3^{\circ} \mathrm{C}\right)$.

Equations $(5.8-5.10)$ indicate that $\psi^{i}$ and $\alpha^{i}$ vary from zero to one and that the relationship between them is approximated by two straightline segments with the discontinuity at $Z=1 / 2$. Experimental data indicate that the relationship for heating is different than for cooling, but that each is essentially independent of outdoor temperature.

The purpose of equations $(5.8-5.10)$ is to provide means for estimating the total input fuel and electric energy $E_{T}^{1}\left(T_{f}\right)$ at any speed and temperature. Accordingly, these equations shall be used in the following calculation procedure:

(a) Determine $\psi^{1 / 2}$ and $\alpha^{1 / 2}$ from equations (5.8 and 5.10) for heating and cooling using measured values of $\dot{Q}_{S s}^{Z}\left(T_{j}\right)$ and $E_{T}^{Z}\left(T_{j}\right),(Z=0,1)$

(b) Determine $\alpha^{i}$ at intermediate speed $z=i$ from equation (5.10).

(c) Determine $\psi^{i}$ from equation (5.9) based upon the results of (a) and $(b)$. 


\section{(d) Determine $E_{T}^{i}\left(T_{j}\right)$ from equation (5.8).}

\subsection{SEASONAL PERFORMANCE FACTOR AND SEASONAL OPERATING COST}

\subsubsection{Single-Speed Operation}

The total heating or cooling done in the $j$ th temperature bin is

$$
Q\left(T_{j}\right)=n_{j} B L\left(T_{j}\right)
$$

where $n_{j}$ is the number of heating or cooling hours in the $j$ th bin, and $\mathrm{BL}\left(\mathrm{T}_{1}\right)$ and $\mathrm{T}_{\text {f }}$ are given by equations (4.1 and 4.2), respectively. The total heating or cooling done during a season is equal to the sumation of the energy in each non-zero temperature bin and may be expressed as

$$
Q=N \sum_{j=1}^{n} \frac{Q\left(T_{j}\right)}{N}=N \sum_{j=1}^{n}\left[\frac{n_{j}}{N}\right] B L\left(T_{j}\right)
$$

$n$ is the number of non-zero temperature bins, $N=\sum_{j=1}^{n} n_{j}$ is the total heating or cooling season hours in all the bins. $\left(n_{j} / N\right)$ are the fractional bin hours and are listed in tables 3 and 4 for residential and commercial/industrial applications, respectively.

When the steady-state heating or cooling capacity at temperature $T_{j}$ is greater than the building load $\left[\dot{Q}_{S S}\left(T_{j}\right)>B L\left(T_{j}\right)\right]$, the total input fuel and electric energy in the $j$ th temperature $b_{i n}{ }^{j}$ is:

$$
E_{T}\left(T_{j}\right)=\frac{n_{j} B L\left(T_{j}\right)}{\operatorname{COP} \text { cyc }_{j}\left(T_{j}\right)}
$$

Equations (5.3, 5.7, and 5.2) may be used to express equation (5.13) in terms of the load factor $X\left(T_{j}\right)$, part-load factor PLF $\left[X\left(T_{j}\right)\right]$, and the input fuel and electric energy $Q_{f}\left(T_{j}\right)$ and $\dot{E}_{s s}\left(T_{j}\right)$. Accordingly:

$$
E_{T}\left(T_{j}\right)=\frac{n_{j} X\left(T_{j}\right)}{\operatorname{PLF}\left(X\left(T_{j}\right)\right)} \cdot\left[\dot{Q}_{f}\left(T_{j}\right)+\frac{3.413}{0.3} \dot{E}_{S S}\left(T_{j}\right)\right]
$$

When BL $\left(T_{j}\right)>\dot{Q}_{S s}\left(T_{1}\right)$, equations $(5.3$ and 5.7$)$ indicate that $X\left(T_{j}\right)=$

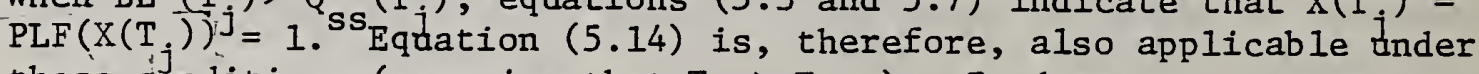
these conditions (assuming that $\mathrm{T}_{j}>\mathrm{T}_{\text {off }}$ ). It does not, however, include the supplemental energy required when $\mathrm{BL}\left(\mathrm{T}_{j}\right)>\dot{Q}_{\mathrm{SS}}\left(\mathrm{T}_{j}\right)$. The total input fuel and electric energy (excluding resistance heat) for the entire heating or cooling season becomes (for $\mathrm{T}_{j}>\mathrm{T}_{\text {off }}$ ): 
$\left.E_{T}=N \sum_{j=1}^{n} \frac{E_{T}\left(T_{j}\right)}{N}=N \sum_{j=1}^{n}\left[\frac{n_{j}}{N}\right]\left[\frac{X\left(T_{j}\right)}{\operatorname{PLF}\left[X\left(T_{j}\right)\right]}\right]\left[\dot{Q}_{f}\left(T_{j}\right)+\frac{3.413}{0.3} \dot{E}_{s s}{ }^{(T} T_{j}\right)\right]$

During heating when $B L\left(T_{j}\right)>\dot{Q}_{s s}\left(T_{j}\right)$, the supplemental energy required in the $j$ th bin is:

$$
Q_{R}\left(T_{j}\right)=n_{j}\left[B L\left(T_{j}\right)-\dot{Q}_{s s}\left(T_{j}\right)\right] / n_{s}
$$

$\eta_{\mathrm{s}}$ is the efficiency of producing the supplemental energy from primary fuel. If electrical resistance is used, it is assumed that $n_{s}=0.3$. The supplemental energy required for the entire heating season becomes:

$Q_{R}=N \sum_{j=n^{\prime}}^{n}, \frac{Q_{R}\left(T_{j}\right)}{N}=N \sum_{j=n^{\prime}}^{n}\left(\frac{n_{j}}{N}\right)\left[B L\left(T_{j}\right)-Q_{s s}\left(T_{j}\right)\right] / n_{s}$ where $n^{\prime}$ is the lowest temperature bin at which $B L\left(T_{j}\right)>\dot{Q}_{S S}\left(T_{j}\right)$. The
seasonal performance factor SPF is defined as:

$$
\mathrm{SPF}=\frac{Q}{\mathrm{E}_{\mathrm{T}}+\mathrm{Q}_{\mathrm{R}}}
$$

Substituting equations $(5.12,5.15,5.17)$, into equation (5.18) yields:

$$
S P F=\frac{\sum_{j=1}^{n}\left[\frac{n_{j}}{N}\right] \text { BL }\left(T_{j}\right)}{\sum_{j=1}^{n}\left(\frac{n}{N}\right) \frac{X\left(T_{j}\right)}{\operatorname{PLF}\left(X\left(T_{j}\right)\right)}\left[\dot{Q}_{f}\left(T_{j}\right)+\frac{3.413}{0.3} \dot{E}_{S s}\left(T_{j}\right)\right]+\sum_{j=n}^{n}\left[\frac{n j}{N}\right]\left[B L\left(T_{j}\right)-\dot{Q}_{S S}\left(T_{j}\right)\right] / n_{s}}
$$

The second summation in the denominator is zero for.cooling calculations. An estimate of the seasonal operating cost SOC, is given by:

$$
\begin{gathered}
\text { SOC = N } \sum_{j=1}^{n}\left[\frac{n_{j}}{N}\right] \frac{X\left(T_{j}\right)}{\operatorname{PLF}\left(X\left(T_{j}\right)\right)}\left[\dot{Q}_{f}\left(T_{j}\right)\left(C_{F}\right)+\left(C_{E}\right) \dot{E}_{s s}\left(T_{j}\right)\right] \\
+{ }_{j=n^{\prime}}^{n}\left[\frac{\vec{n}_{j}}{N}\right]\left[\frac{C_{s}}{n_{s}}\right]\left[B L\left(T_{j}\right)-\dot{Q}_{s s}\left(T_{j}\right)\right]
\end{gathered}
$$


$C_{F}, C_{E}$, and $C_{S}$ denotes the cost of engine fuel ( $\left.\$ / B t u\right)$, the cost of electric energy ( $\$ / W h)$, and the cost of supplemental energy ( $\$ / B t u)$. If the supplemental energy is electric resistance heat, then $C_{S}=C_{E}$ and $n_{s}=1$. As before, the second summation is zero during cooling. The average total bin hours for heating and cooling, and for either climate and for both building applications are given in table 5. The steadystate capacity $\dot{Q}_{s s_{j}}\left(T_{j}\right)$, input electric energy $\dot{E}_{S s}\left(T_{j}\right)$, and input fuel energy $\dot{Q}_{f}\left(T_{j}\right)$ at bin temperatures other than the test points shall be determined fiom linear interpolation of the test data as described in section 5.1 .

The residential or commercial/industrial SPF and SOC shall be determined from equations (5.19) and (5.20) for both the heating and cooling seasons, and for either climate. Table 6 is a calculation sheet which may be used for systematically calculating these seasonal parameters.

\subsubsection{Two-Speed/Dual-Capacity Operation}

The seasonal performance factor SPF and the seasonal operating cost SOC of those engine-driven systems with two-speed compressor capability, or with some other means of achieving dual-capacity operation, are determined from:

$$
\begin{aligned}
& S P F=\frac{\sum_{j=1}^{n}\left[\frac{n_{j}}{N}\right] B L\left(T_{j}\right)}{\sum_{j=1}^{n} \frac{E_{T}\left(T_{j}\right)}{N}+j=\sum_{n}{ }^{n} \frac{Q_{R}\left(T_{j}\right)}{N}} \\
& S O C=N\left\{\sum_{j=I}^{n} \frac{E_{T}^{\prime}\left(T_{j}\right)}{N}+C_{s} \sum_{j=}^{n} \frac{Q_{R}\left(T_{j}\right)}{N}\right\}
\end{aligned}
$$

where $n_{j}, N, n^{\prime}$, and $C_{s}$ are defined in section 5.4 .1 , and $\left[\mathrm{n}_{j} / \mathrm{N}\right]$ are listed in tables 3 and $4 . E_{T}\left(T_{j}\right)$ represents the total fuel and electric energy input to the $j$ th temperature bin, $E_{T}^{\prime}\left(T_{j}\right)$ represents the total cost of that energy, and $Q_{R}\left(T_{j}\right)$ denotes any supplemental energy required. Evaluation of these quantities is discussed subsequently. The building load $\mathrm{BL}\left(\mathrm{T}_{j}\right)$ is given by:

$$
\begin{aligned}
& \mathrm{BL}\left(\mathrm{T}_{j}\right)=\dot{Q}_{S S}^{1}(H D T)(5 j-2) /\left(\mathrm{T}_{c}+5\right), \quad T_{j}<T_{c} \\
& \mathrm{BL}\left(\mathrm{T}_{j}\right)=\dot{Q}_{S S}^{1}(95)(5 j-3) /\left(95-T_{c}\right), \quad T_{j}>T_{c}
\end{aligned}
$$


where the superscript 1 denotes high-speed (greatest capacity) operation, and superscript 0 will subsequently denote low-speed (smallest capacity) operation.

The steady-state heating and cooling capacities $\dot{Q}^{Z}\left(T_{j}\right)$, electrical power input $\dot{E} 2$ and input fuel energy rate $\dot{Q}_{\dot{f}}$ (T $S$ required in subsequent calculations at bin temperatures other than the test points shall be calculated (as described in section 5.1) through interpolation of the two test points adjacent to the bin temperature in question. As shown in figure 2, low speed $(\mathrm{Z}=0)$ tests are conducted over the $47^{\circ} \mathrm{F}$ to $17^{\circ} \mathrm{F}$ temperature range, and high speed $(\mathrm{Z}=1)$ tests are conducted over the $17^{\circ}$ F to $-13^{\circ}$ Erange. Tables 3 and 4 give the bin temperatures which correspond to the test points for residential and commercial/industrial applications, respectively. If the bin temperature in question lies outside the range of test points, the result shall be linearly extrapolated from the two closest test points.

$E_{T}\left(T_{j}\right) / N, E_{T}^{\prime}\left(T_{j}\right) / N$, and $Q_{R}\left(T_{i}\right) / N$ required in equations (5.21 and 5.22) are determined according to the operating regimes $I-I V$ discussed below:

\section{Regime I:}

$\mathrm{BL}\left(\mathrm{T}_{\dot{j}}\right)<\dot{Q}_{\mathrm{SS}}^{0}\left(\mathrm{~T}_{\dot{q}}\right)$ and the system cycles between off and low-speed (smallest capacity) operation in order to meet the building load. It is assumed that $\mathrm{T}_{j}>\mathrm{T}_{\text {off }} \cdot$

$$
\frac{E_{T}\left(T_{j}\right)}{N}=\left[\frac{n_{j}}{N}\right] \frac{X^{0}\left(T_{j}\right)}{\operatorname{PLF}\left[X^{0}\left(T_{j}\right)\right]}\left[\dot{Q}_{f}^{0}\left(T_{j}\right)+3.413\left[\frac{\dot{E}_{S S}^{0}\left(T_{j}\right)}{0.3}\right]\right]
$$

$$
\frac{E_{T}^{\prime}\left(T_{j}\right)}{N}=\left[\frac{n_{j}}{N}\right] \frac{x^{0}\left(T_{j}\right)}{\operatorname{PLF}^{0}\left[\left(x^{0}\left(T_{j}\right)\right]\right)}
$$$$
\left[\dot{Q}_{f}^{0}\left(T_{j}\right)\left(C_{F}\right)+\left(C_{E}\right) \dot{E}_{S S}^{0}\left(T_{j}\right)\right](5.25)
$$

$$
\frac{Q_{R}\left(T_{j}\right)}{N}=0
$$

where

$$
\begin{aligned}
X^{0}\left(T_{j}\right) & =\frac{B L\left(T_{j}\right)}{\dot{Q}_{S S}^{0}\left(T_{j}\right)} \\
\operatorname{PLF}^{0}\left[X^{0}\left(T_{j}\right)\right] & =C_{D}^{0}\left[1-X^{0}\left(T_{j}\right)\right]
\end{aligned}
$$




\section{Regime II:}

$\mathrm{BL}\left(\mathrm{T}_{j}\right)>\dot{\mathrm{Q}}_{\mathrm{SS}}^{I}\left(\mathrm{~T}_{j}\right)$ and the system operates continuously at high-speed (greatest capacity) with supplemental heat required during the heating mode to meet the building load.

$$
\begin{aligned}
& \frac{E_{T}\left(T_{j}\right)}{N}=\left[\frac{n_{j}}{N}\right]\left[\dot{Q}_{f}^{1}\left(T_{j}\right)+3.413\left(\frac{\dot{E}_{S S}^{1}\left(T_{j}\right)}{0.3}\right)\right] \\
& \frac{E_{T}^{\prime}\left(T_{j}\right)}{N}=\left[\frac{n_{j}}{N}\right]\left[\dot{Q}_{f}^{1}\left(T_{j}\right)\left[C_{F}\right]+\left[C_{E}\right] \dot{E}_{S S}^{1}\left(T_{j}\right)\right] \\
& \frac{Q_{R}\left(T_{j}\right)}{N}=\left[\frac{n_{j}}{N}\right]\left[\frac{B L\left(T_{j}\right)-\dot{Q}_{S S}^{1}\left(T_{j}\right)}{n_{S}}\right]
\end{aligned}
$$

If $T_{j} \overline{<} T_{\text {off }}, \dot{Q}_{f}^{1}\left(T_{j}\right)=\dot{E}_{s S}^{1}\left(T_{j}\right)=\dot{Q}_{s S}^{1}\left(T_{j}\right)=0$, and $S P F=\eta_{s}$

\section{Regime III:}

$\dot{Q}_{S S}^{0}\left(T_{j}\right) \overline{<L}\left(T_{j}\right)<\dot{Q}_{S S}^{1}\left(T_{j}\right)$ and the system cycles between off and highspeed (greatest capacity) operation in order to meet the building load. It is assumed that $\mathrm{T}_{j}>\mathrm{T}_{\text {off }}$.

$$
\begin{aligned}
& \frac{E_{T}\left(T_{j}\right)}{N}=\left[\frac{n_{j}}{N}\right] \frac{x^{1}\left(T_{j}\right)}{P L F^{1}\left(x^{1}\left(T_{j}\right)\right)}\left[Q_{f}^{1}\left(T_{j}\right)+3.413\left[\frac{E_{s S_{j}^{1}}\left(T_{j}\right)}{0.3}\right]\right] \\
& \frac{E_{T}^{\prime}\left(T_{j}\right)}{N}=\left[\frac{n_{j}}{N}\right] \frac{x^{1}\left(T_{j}\right)}{P L F^{1}\left(X^{1}\left(T_{j}\right)\right)}\left[\dot{Q}_{f}^{1}\left(T_{j}\right)\left(C_{F}\right)+\left(C_{E}\right) \dot{E}_{s s^{1}}\left(T_{j}\right)\right] \\
& \frac{Q_{R}\left(T_{j}\right)}{N}=0
\end{aligned}
$$

where $x^{1}\left(T_{j}\right)=\frac{B L\left(T_{j}\right)}{Q_{S S}^{1}\left(T_{j}\right)}$

$$
\operatorname{PLF}{ }^{1}\left(X^{1}\left(T_{j}\right)\right)=1-C_{D}^{1}\left[1-X^{1}\left(T_{j}\right)\right]
$$


Regime IV:

$\dot{Q}_{S S}^{0}\left(T_{\dot{j}}\right) \overline{B L}\left(T_{i}\right)<\dot{Q}_{S S}^{I}\left(T_{i}\right)$ and the system cycles between high-speed (gSreatest capacity) operation and low-speed (smallest capacity) operation. It is assumed that $\mathrm{T}_{j}>\mathrm{T}_{\text {off }} \cdot$

$$
\begin{aligned}
\frac{E_{T}\left(T_{j}\right)}{N}= & {\left[\frac{n_{j}}{N}\right]\left\{x^{0}\left(T_{j}\right)\left[\dot{Q}_{f}^{0}\left(T_{j}\right)+3.413\left(\frac{\dot{E}_{S S}^{0}\left(T_{j}\right)}{0.3}\right)\right]\right.} \\
+ & \left.x^{1}\left(T_{j}\right)\left[\dot{Q}_{f}^{1}\left(T_{j}\right)+3.413\left(\frac{\dot{E}_{S S}^{1}\left(T_{j}\right)}{0.3}\right)\right]\right\} \\
\frac{E_{T}^{\prime}\left(T_{j}\right)}{N}= & {\left[\frac{n_{j}}{N}\right]\left\{x^{0}\left(T_{j}\right)\left[\dot{Q}_{f}^{0}\left(T_{j}\right)\left(C_{F}\right)+\left(C_{E}\right) \dot{E}_{S S}^{0}\left(T_{j}\right)\right]\right.} \\
+ & \left.x^{1}\left(T_{j}\right)\left[\dot{Q}_{f}^{1}\left(T_{j}\right)\left(C_{F}\right)+\left(C_{E}\right) \dot{E}_{S S}^{1}\left(T_{j}\right)\right]\right\}
\end{aligned}
$$

$$
\frac{Q_{R}\left(T_{j}\right)}{N}=0
$$

where $X^{0}\left(T_{j}\right)=\frac{\dot{Q}_{S S}^{I}\left(T_{j}\right)-B L\left(T_{j}\right)}{\dot{Q}_{S S}^{I}\left(T_{j}\right)-\dot{Q}_{S S}^{0}\left(T_{j}\right)}$

$$
X^{1}\left(T_{j}\right)=1-x^{0}\left(T_{j}\right)
$$

The residential and commerciai/industrial SPF and SOC of two-speed/dualcapacity heat pump systems shall be determined from equations 5.21 and 5.22 for both seasons and for either climate using equations 5.23 5.41 as required. Table 7 is a calculation sheet which may be used for systematically calculating these seasonal parameters.

\subsubsection{Variable-Speed Operation}

The evaluation of the seasonal performance factor SPF and the seasonal cost of operation SOC of variable speed heat pumps is very similar to the procedure described in section 5.4.2 for two-speed heat pumps. The SPF and SOC are given by equations 5.21 and 5.22 , respectively. The building load $\mathrm{BL}\left(\mathrm{T}_{\dot{f}}\right)$ is given by equation 5.23 , and the steady-state heating and cooling capacity $\dot{Q}_{S S}\left(T_{j}\right)$, electrical power input $\dot{\mathrm{E}}_{S S}\left(\mathrm{~T}_{\dot{j}}\right)$, and input fuel energy $\dot{Q}_{f}\left(T_{j}\right)$ are determined from linear interpolation of 
adjacent test points. Superscripts 0 and 1 shall designate minimum and maximum speed, respectively. The total input fuel and electric energy $E_{T}\left(T_{j}\right) / N$, its total cost $E_{T}\left(T_{j}\right) / N$, and the supplemental heat required are determined according to operating regimes I-III. Regimes I $\left[B L\left(T_{j}\right)<\dot{Q}_{S S}^{0}\left(T_{j}\right)\right]$ and $I I\left[B L\left(T_{j}\right)>\dot{Q}_{S S}^{1}\left(T_{j}\right)\right]$ are exactly the same as in section 5.4.2. $E_{T}\left(T_{j}\right) / N, E_{T}{ }^{\prime}\left(T_{j}\right) / N$, and $Q_{R}\left(T_{j}\right) / N$ are given by equations $5.24-5.26$ for regime $I$ and by equations $5.29-5.31$ for regime II.

Regime III:

$\dot{Q}_{S S}^{0}\left(T_{j}\right)<B L\left(T_{j}\right)<\dot{Q}_{S S}^{1}\left(T_{j}\right), T_{j}>T_{o f f}$, and the system is operating continuously at a speed such that $\dot{Q}_{S S}^{I}(T j)=B L\left(T_{j}\right)$. Therefore, $Q_{R}\left(T_{j}\right) /$ $N=0$ and $X\left(T_{i}\right)=P L F\left[X\left(T_{j}\right)\right]=1$. Superscript $i$ denotes normalized intermediate-speed $(\mathrm{Z} \stackrel{i}{i})$. The total input fuel and electric energy are obtained from equation 5.8 .

$$
\begin{aligned}
& \frac{E_{T}\left(T_{j}\right)}{N}=\frac{E_{T}^{i}\left(T_{j}\right)}{N}=\frac{E_{T}^{0}\left(T_{j}\right)}{N}+\psi^{i}\left[\frac{E_{T}^{1}\left(T_{j}\right)}{N}-\frac{E_{T}^{0}\left(T_{j}\right)}{N}\right] \\
& \frac{E_{T}^{\prime}\left(T_{j}\right)}{N}=\frac{E_{T}^{i}\left(T_{j}\right)^{\prime}}{N}=\frac{E_{T}^{0}\left(T_{j}\right)^{\prime}}{N}+\psi^{i}\left[\frac{E_{T}^{1}\left(T_{j}\right)^{\prime}}{N} \frac{E_{T}^{0}\left(T_{j}\right)^{\prime}}{N}\right] \\
& \text { where } \frac{E_{T}^{0}\left(T_{j}\right)}{N}=\left[\frac{n_{j}}{N}\right]\left[\dot{Q}_{f}^{0}\left(T_{j}\right)+3.413\left(\frac{\left.\dot{E}_{s s_{j}^{0}\left(T_{j}\right)}^{0.3}\right)}{0.3}\right]\right. \\
& \frac{\dot{E}_{T}^{1}\left(T_{j}\right)}{N}=\left[\frac{n_{j}}{N}\right] \quad\left[\dot{Q}_{f}^{1}\left(T_{j}\right)+3.413\left(\frac{\dot{E}_{S S}^{1}\left(T_{j}\right)}{0.3}\right)\right] \\
& \frac{E_{T}^{0}\left(T_{j}\right)^{\prime}}{N}=\left[\frac{n_{j}}{N}\right]\left[\dot{Q} Q\left(T_{j}\right)\left(C_{F}\right)+\left(C_{E}\right) \dot{E}_{s S^{0}}\left(T_{j}\right)\right] \\
& \frac{\left(E_{T}^{1}\left(T_{j}\right)^{\prime}\right.}{N}=\left[\frac{n_{j}}{N}\right]\left[\dot{Q}_{f}^{1}\left(T_{j}\right)\left(C_{F}\right)+\left(C_{E}\right) \dot{E}_{s s^{1}}\left(T_{j}\right)\right]
\end{aligned}
$$


$\psi^{i}$ is the normalized part-speed input energy factor and is given by equation 5.9 as a function of the normalized part-speed capacity factor $\alpha^{i}$. $\alpha^{\mathcal{L}}$, in turn, is deterpined at infermediate speed $z=i$ from equation $5.10^{\circ}$. The values of $\psi^{1 / 2}$ and $\alpha^{1 / 2}$ required in equation 5.9 are determined for both heating and cooling from equations 5.8 and 5.10 . Table 7 is a calculation sheet which may be used to systematically calculate the heating and cooling SPF and SOC of variablespeed systems for both seasons, and for either climate or building application.

\subsection{FROST ACCUMULATION AND DEFROST CALCULATIONS}

The frost degradation coefficient $C_{\text {def }}$, is defined by:

$$
c_{\text {def }}=\frac{\operatorname{COP}_{\text {def }}(32)}{\operatorname{COP}_{\text {ss }}(32)}
$$

where COP (32) is the steady-state coefficient of performance at the $32^{\circ} \mathrm{F}\left(0^{\circ} \mathrm{C}\right)^{5}$ test point. It is determined from equation 5.2 using the

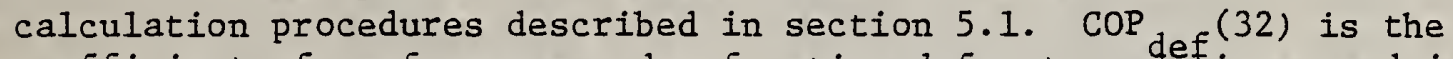
coefficient of performance under frosting-defrost condefions, and is determined from:

$$
\mathrm{COP}_{\operatorname{def}}(32)=\frac{Q_{\mathrm{def}}(32)}{Q_{f}(32)+\frac{3.413}{0.3} E_{\operatorname{def}}(32)}
$$

$Q_{f}(32)$ is the total input fuel energy during the complete frost accumulation and defrost test. It is based upon the mass (or volume) of fuel consumed and the fuel's LHV. E $E_{\text {fef }}(32)$ is the total input electric energy measured during the test. $\mathrm{Q}_{\mathrm{def}}(32)$ is the net heating done during the test period, and is determined from:

$$
\mathrm{Q}_{\mathrm{def}}(32)=\frac{60 \dot{\mathrm{v}} c_{\mathrm{pa}} \Gamma}{\mathrm{v}_{\mathrm{n}}^{\top}\left(1+\mathrm{w}_{\mathrm{n}}\right)}
$$

$$
\text { where } \left.\quad \Gamma=\int T_{a 2}(t)-T_{a 1}(t)\right] d t
$$

and $\dot{\mathrm{V}}, \mathrm{c}_{\mathrm{pa}}, \mathrm{v}_{\mathrm{n}}{ }^{\prime}, \mathrm{W}_{\mathrm{n}}, \mathrm{T}_{\mathrm{a} 2}(\mathrm{t})$, and $\mathrm{T}_{\mathrm{al}}(\mathrm{t})$ are given in the nomenclature. The flowrate $\dot{V}$ shall be an average value calculated at several intervals throughout the heating portion of the test. For those systems without indoor-air circulating fans, the calculated heating done and the measured input electric energy shall be adjusted for the effect of a fan. The 
correction procedure shall be the same as that described in section 5.1 for steady-state tests, except that the correction shall equal the total energy transferred during the time of fan operation instead of a fixed energy rate.

\section{RECOMMENDED RATING REQUIREMENTS}

The objective of the procedures recommended in this study has been to provide fair and accurate methods for testing prototy'te engine-driven heat pump systems having different design characteristics, and for estimating their seasonal performance and seasonal operating cost. Inherent in this objective is a requirement that the results of the tests and calculations be reported in such a way that the performance of different prototype systems may be effectively compared. Table 8 is a rating sheet which requires that the system under test be rated relative to its:

(a) Steady-state capacity $\dot{Q}_{S s}\left(T_{j}\right)$, at the ARI rating points of $95^{\circ} \mathrm{F}\left(35^{\circ} \mathrm{C}\right), 47^{\circ} \mathrm{F}\left(8.3^{\circ} \mathrm{C}\right)^{\circ}$, and $17^{\circ} \mathrm{F}\left(-8.3^{\circ} \mathrm{C}\right)$, respectively.

(b) Steady-state coefficient of performance $\operatorname{COP}_{S s}\left(T_{j}\right)$, at the ARI rating points.

(c) Seasonal performance factor SPF, for both heating and cooling.

(d) Seasonal operating cost SOC, for both heating and cooling.

(e) Frost degradation factor, $C_{\text {def }}$.

The seasonal parameters SPF and SOC shall be based upon the residential building application for those systems which have cooling capacities at the ARI rating point of $60,000 \mathrm{Btu} / \mathrm{hr}(17.6 \mathrm{~kW})$ or less. The light commercial/industrial building application shall apply for those systems with cooling capacities greater than $60,000 \mathrm{Btu} / \mathrm{hr}(17.6 \mathrm{~kW})$.

\section{LIMITATIONS OF THE RECOMMENDED TEST AND RATING PROCEDURES}

There are a number of limitations associated with the recommended test and rating procedures. Some are inherent in any test and rating program which attempts to characterize the performance of a system based upon a finite and small number of test points. These limitations are almost unavoidable and will not be discussed. The remaining limitations are more fundamental and indicate a need for further investigation. These are discussed below:

(a) As discussed in section 2.2 and illustrated in figures 1-3 and table 1 , there are a large number of steady-state tests required. It is felt that these tests are required to adequately predict the performance of the system over a broad range of outdoor temperatures. As more operating data becomes available on engine-driven systems, however, it may be possible to eliminate some of the steady-state tests. 
(b) Cyclic testing of different engine-driven heat pump systems is required under a variety of ambient conditions and cycling rates. These tests should confirm and improve the accuracy and generality of the procedure discussed in section 5.2 for determining cyclic performance degradation. It is conceivable that sufficient testing may lead to a default $C_{D}$ which may be predicted based upon a system's design and operating mode. If such a prediction was possible, it might eliminate the need for costly and time-consuming cyclic testing.

(c) It was noted in section 2.4 that the ideal way to account for the deteriorating effects of frost on the outdoor coil would be to apply a correction factor to all steady-state perfor:mance data obtained within the frost range, but that insufficient data currently exists to establish that correction factor. Laboratory and field testing over a range of outdoor temperatures and relative humidities is therefore required in order to develop a general frost correction which may be effectively applied to a broad range of engine-driven heat pump systems.

(d) The recommended test and rating procedures have assumed that the engine's waste heat is diverted to the outdoor side during the cooling mode, and is therefore not utilized. While this approach is generally justified for engine-driven systems designed for northern climates where the cooling load is low relative to the heating load, it will be unfair to those systems which are located in southern climates and are designed to utilize the waste heat for such purposes as domestic or commercial hot water heating. Under these circumstances the test and rating procedures should be modified to credit the heat pump system with engine waste heat utilization. This will require changes in the instrumentation requirements, test requirements, and calculation procedures. In addition, seasonal performance factor and seasonal operating cost determinations will require the specification of a generalized domestic or commercial hot water heating load. Also required is the specification of an alternate means of supplying energy to heat the hot water when the heat pump system is on the "off" part of its operating cycle.

(e) The recommended test and rating procedures have been limited to prototype, air-to-air, mechanical compression heat pump systems. These procedures could readily be modified for application to possible future commercially produced systems. Considerable work would be required, however, to adapt these procedures to absorption systems, or to mechanical compression systems which do not use ambient air as the heat source or heat sink medium. 


\section{References}

1. Gordian Associates, Inc., "Heat Pump Technology," Report Prepared for the U.S. Department of Energy, Dec. 1977, pp. 72-93.

2. Auxer, W. L., "Development of a Stirling Engine Powered Heat Activated Heat Pump,": Proceedings of the 12th Intersociety Energy Conversion Engineering Conference, Washington, D.C., Sept. 1977, pp. 397-401.

3. Friedman, D., "Light Commercial Brayton/Rankine Space Conditioning System," Proceedings of the 12 th Intersociety Energy Conversion Engineering Conference, Washington, D.C., Sept. 1977, pp. 172-178.

4. Swenson, P. F., and Rose, R. K., "Development of the High Seasonal Performance Factor Gas Heat Pump," Proceedings of the 12 th Intersociety Energy Conversion Engineering Conference, Washington, D.C., Sept. 1977, pp. 390-396.

5. Sarkes, L. A., Nicholls, J. A., and Menzer, M. S. "Gas-Fired Heat Pumps: An Emerging Technology," ASHRAE Journal, Mar. 1977, pp. 36-41.

6. Kelly, G. E., and Parken, W. H. Jr., "Method of Testing, Rating and Estimating the Seasonal Performance of Central Air-Conditioners and Heat Pumps Operating in the Cooling Mode," National Bureau of Standards, Washington, D.C., NBSIR 77-1271, April 1978.

7. Parken, W. H., Kelly, G. E., and Didion, D. A., "Method of Testing, Rating and Estimating the Heating Seasonal Performance of Heat Pumps," National Bureau of Standards, Washington, D. C. (in publication).

8. Kline, S. J., and McClintock, F. A., "Describing Uncertainties in Single-Sample Experiments," Mechanical Engineering, January 1953. 


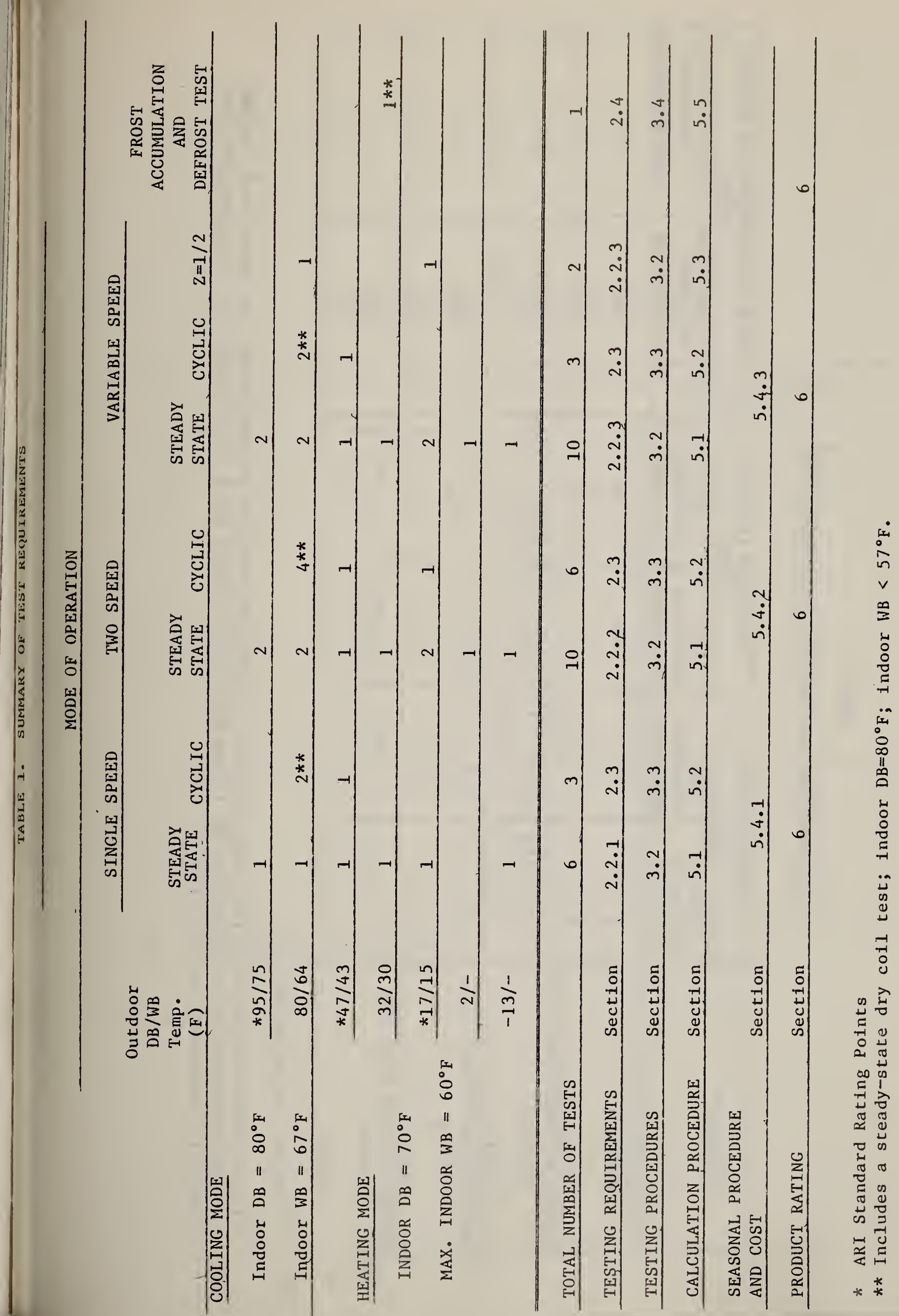




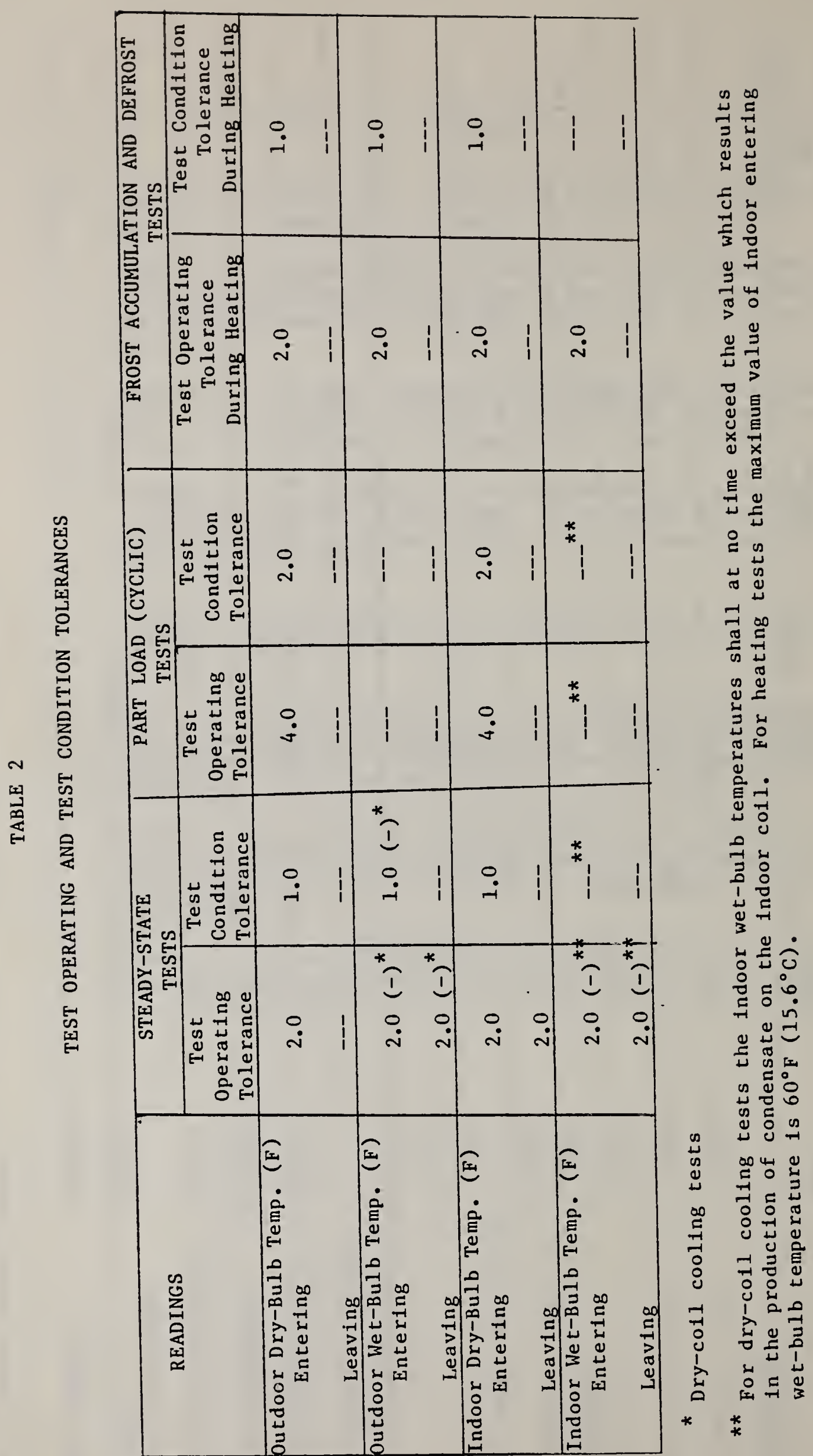


TABLE 3

GEINERALIZED CLILATES FOR RESIDENTIAL APPLICATIONS

\begin{tabular}{|c|c|c|c|c|c|}
\hline & \multirow{2}{*}{$\begin{array}{l}\text { Temperature } \\
\text { Bin Number } \\
\quad j\end{array}$} & \multirow{2}{*}{$\begin{array}{l}\text { Representative } \\
\text { Bin Temperature } \\
\qquad T_{j}(F)\end{array}$} & \multirow{2}{*}{$\begin{array}{l}\text { Bin Temperature } \\
\text { Range } \\
\text { (F) }\end{array}$} & \multicolumn{2}{|c|}{$\begin{array}{l}\text { Fraction of Total Temperature } \\
\text { Bin Hours, } \pi_{j} / N\end{array}$} \\
\hline & & & & $\begin{array}{l}\text { Northern } \\
\text { Climate }\end{array}$ & $\begin{array}{l}\text { Southern } \\
\text { Climate }\end{array}$ \\
\hline $\begin{array}{l}\text { it } \\
\text { E } \\
\text { d } \\
\text { T } \\
\text { I } \\
\text { it } \\
G\end{array}$ & $\begin{array}{r}1 \\
2 \\
3 \\
* \# 4 \\
5 \\
6 \\
* \quad 7 \\
8 \\
9 \\
* * 10 \\
11 \\
12 \\
* 13 \\
14 \\
15 \\
* 16\end{array}$ & $\begin{array}{r}62 \\
57 \\
52 \\
47 \\
42 \\
37 \\
32 \\
27 \\
22 \\
17 \\
12 \\
7 \\
2 \\
-3 \\
-8 \\
-13\end{array}$ & $\begin{array}{c}60-64 \\
55-59 \\
50-54 \\
45-49 \\
40-44 \\
35-39 \\
30-34 \\
25-29 \\
20-24 \\
15-19 \\
10-14 \\
5-9 \\
0-4 \\
(-5)-(-1) \\
(-10)-(-6) \\
(-15)-(-11)\end{array}$ & $\begin{array}{l}.115 \\
.106 \\
.096 \\
.092 \\
.097 \\
.109 \\
.118 \\
.086 \\
.058 \\
.039 \\
.028 \\
.020 \\
.015 \\
.010 \\
.006 \\
.003\end{array}$ & $\begin{array}{l}.155 \\
.139 \\
.136 \\
.133 \\
.129 \\
.115 \\
.091 \\
.052 \\
.026 \\
.013 \\
.005 \\
.002 \\
.001 \\
-- \\
-- \\
--\end{array}$ \\
\hline $\begin{array}{l}C \\
0 \\
0 \\
\text { L } \\
\text { I } \\
\therefore \\
\text { G }\end{array}$ & $\begin{array}{l}1 \\
2 \\
3 \\
4 \\
5 \\
6 \\
7 \\
3\end{array}$ & $\begin{array}{r}67 \\
72 \\
77 \\
82 \\
87 \\
92 \\
97 \\
102\end{array}$ & $\begin{array}{r}65-69 \\
70-74 \\
75-79 \\
30-84 \\
85-89 \\
90-94 \\
95-99 \\
100-104\end{array}$ & $\begin{array}{l}.293 \\
.271 \\
.200 \\
.131 \\
.071 \\
.028 \\
.005 \\
0\end{array}$ & $\begin{array}{l}.213 \\
.238 \\
.201 \\
.153 \\
.110 \\
.059 \\
.023 \\
.003\end{array}$ \\
\hline
\end{tabular}

* Steady-state testing point

if Standard ARI rating point 
TABLE 4

GENERAL IZED CLILATES FOR COMMERCIAL/IKDUSTRIAL APPLICATIONS

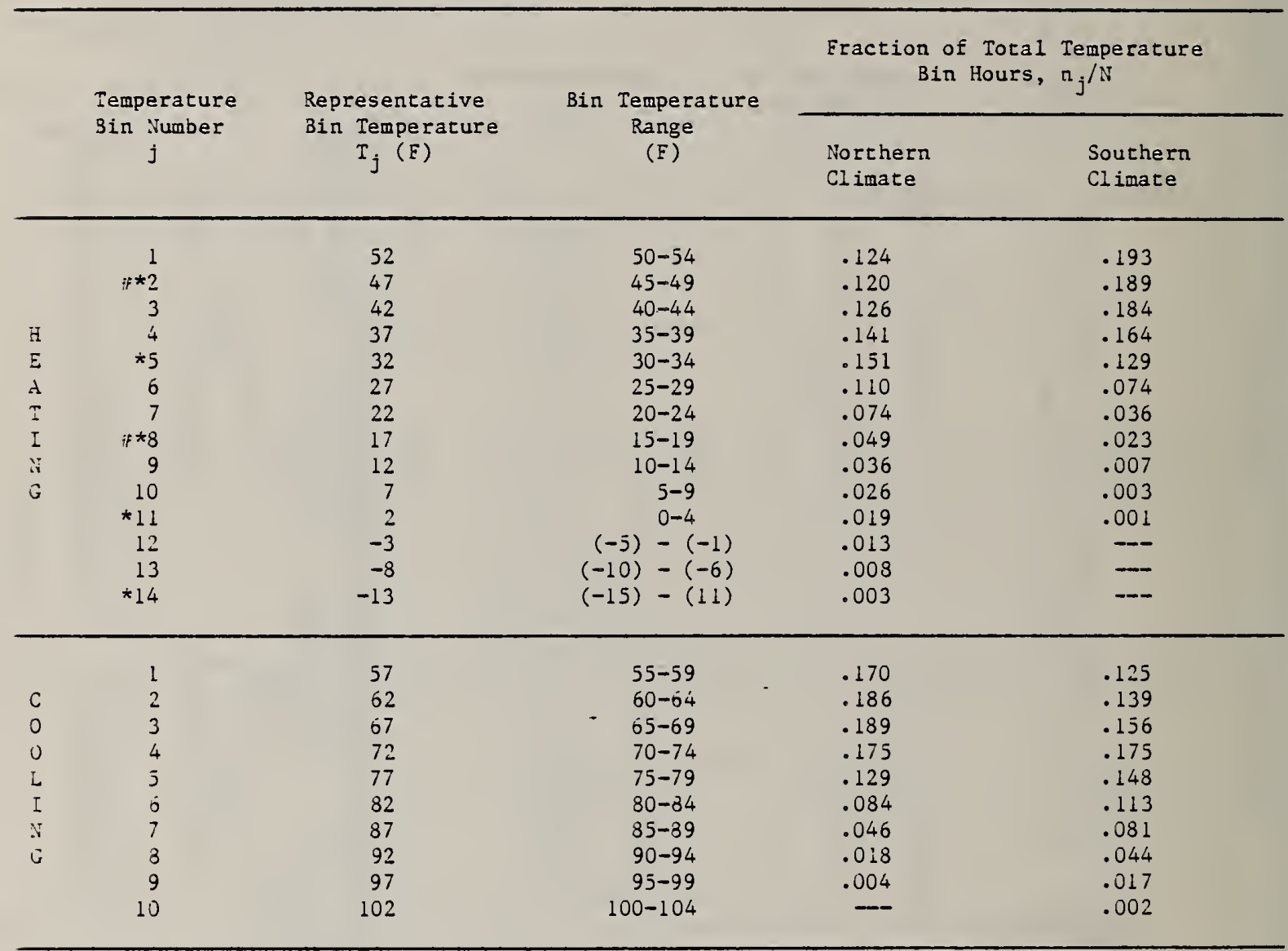

* Steady-state testing point

* Standard ARI rating point 
TABLE 5

SUMMARY WEATHER DATA FOR REPRESENTATIVE CLDIATES

Avg. Total Bin Hours

Generalized

Climate

Degree Heating Design

Days

(DD)

Temperature ( $F)$

(HDT)

Building

Application

Heating Cooling

(BHH)

(BHC)

\begin{tabular}{|c|c|c|c|c|c|}
\hline \multirow{2}{*}{ Northern } & \multirow{2}{*}{7000} & \multirow{2}{*}{-5} & Residential & 6240 & 2497 \\
\hline & & & Comm./Ind。 & 4877 & 3860 \\
\hline \multirow{2}{*}{ Southern } & \multirow{2}{*}{3500} & \multirow{2}{*}{15} & Residential & 4800 & 3980 \\
\hline & & & Comm•/Ind. & 3388 & 5391 \\
\hline
\end{tabular}


MODE OF OPERATION: $\square$ Heating $\square$ Cooling BUIIDING APPLICATION: $\square$ Residential $\square$ Commercial/Industrial CIMATE: $\square$ Northern $\square$ Southern

Bin Hours Heating: $\quad \mathrm{BHH}=$ (HRS) Bin Hours Cooling: $\quad \mathrm{BHC}=$ (HRS) Supplemental Heat Generating Efficiency: $\eta_{\mathrm{S}}=$ $(\%)$






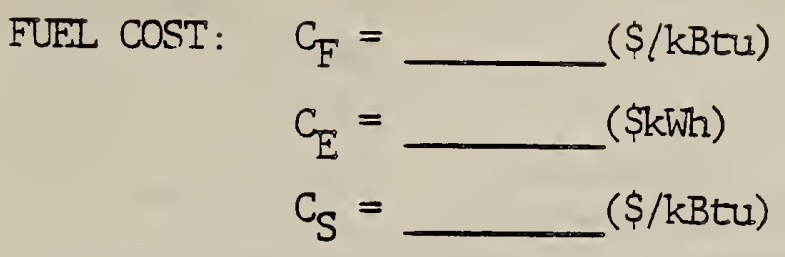



Ref. 1: Table 3 or 4

Ref. 2: Interpolation of Test Data

Ref. 3: Use eqn. (4.1)

Ref. 4: Use eqn. (5.3)

Ref. 5: Use eqn. (5.7)

Ref. $6: Q\left(T_{j}\right) / N=(\operatorname{col} . C)(\operatorname{col} . G)$

Ref. 7: (Fuel + Electric Energy) $/ N=\left[\frac{(\operatorname{col} . C)(\operatorname{col} . \mathrm{H})}{(\mathrm{col} . \mathrm{I})}\right]\left[\operatorname{col} . F+\frac{3.413(\mathrm{col} . \mathrm{E})}{0.3}\right]$

Ref. 8: (Supolemental Energy) $/ N=(\operatorname{col} . C)(\operatorname{col} . G-\operatorname{col} . D) / / \mathrm{S}$

Ref. 9: (Fuel + elect. energy cost) $/ \mathbb{N}=\left[\frac{(\operatorname{col} . C)(\operatorname{col} . H)}{(\operatorname{col} . I)}\right]\left[(\operatorname{col} . F)\left(C_{F}\right)+\left(C_{E}\right)(\operatorname{col} . E)\right]$

Ref. 10: (Supplemental energy cost) $/ \mathrm{N}=\left(\mathrm{C}_{\mathrm{S}}\right)(\operatorname{col} . \mathrm{L})$ 
TABLE 7. CALCULATION STEET FOR TWO-SPEED/DUAL CAPACITY OR VARIABLE-SPEED IFAT PLMPS

SYSTEM TYPE: $\square$ Two-Speed $\square$ Variable Speed

MODE OF OPERATTON: $\square$ Heating $\square$ cooling

BUIIDING APPLICATION: $\square$ Residential $\square$ Conmercial/Industrial

CLIMATE: $\square$ Northem $\square$ Southern

Bin Hours - Heating: BHH =

Bin Hours - Cooling: $\mathrm{BHC}=$

Supplemental Heat Generating Efficiency: $\eta_{\mathrm{s}}=$ (\%)

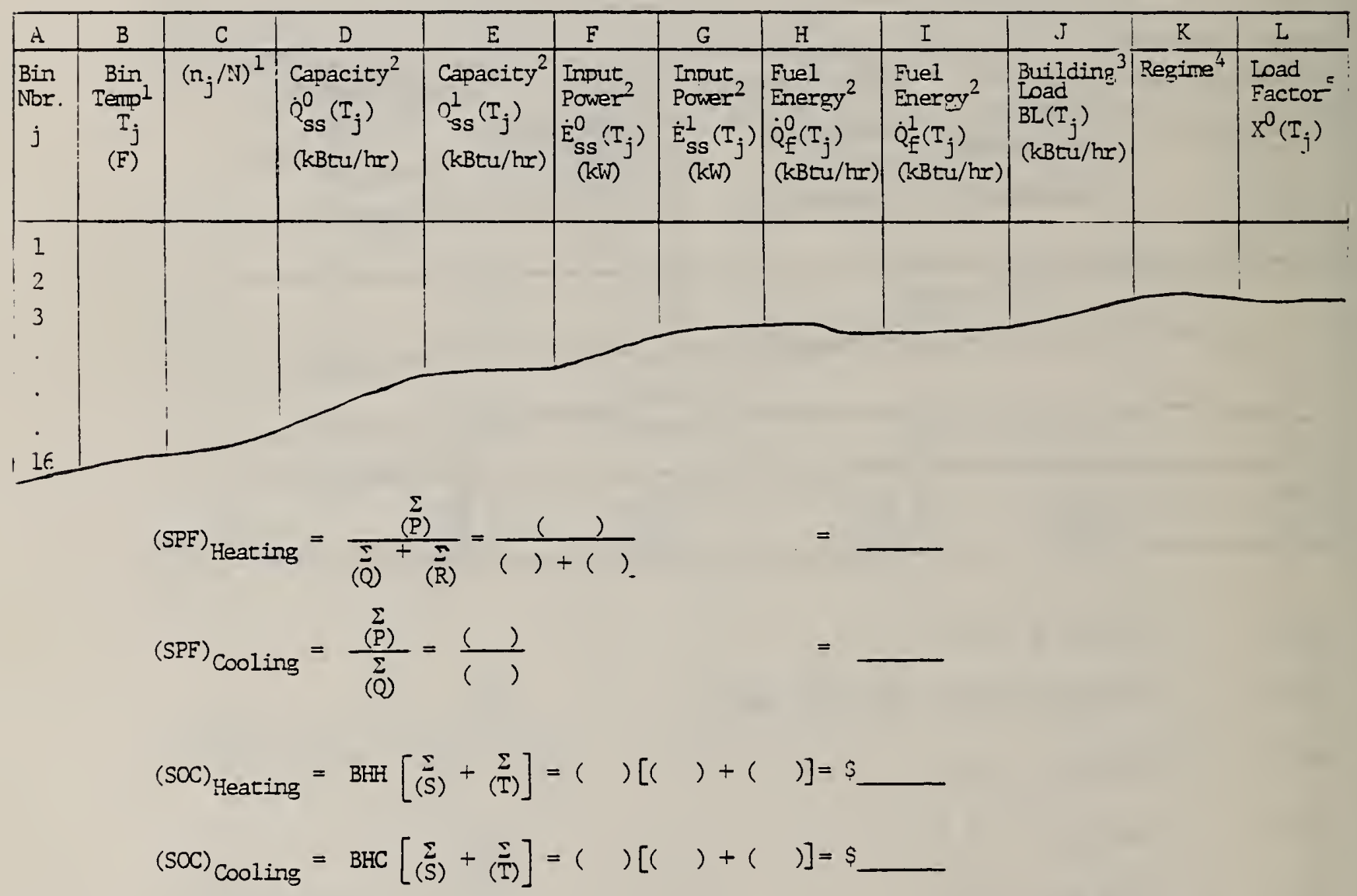




$$
\text { EUEI COST: } \begin{aligned}
C_{F} & =\longrightarrow \\
C_{E} & =\longrightarrow \\
C_{S} & =\longrightarrow
\end{aligned}
$$

FOR VARTABLF--SPFED DPERATION:

$$
\begin{array}{r}
1 / 2=\ldots \text { (Heating). } \ldots \text { (Cooling) } \\
\Psi^{1 / 2}=\ldots \text { (Feating). }{ }^{\text {(Cooling) }}
\end{array}
$$

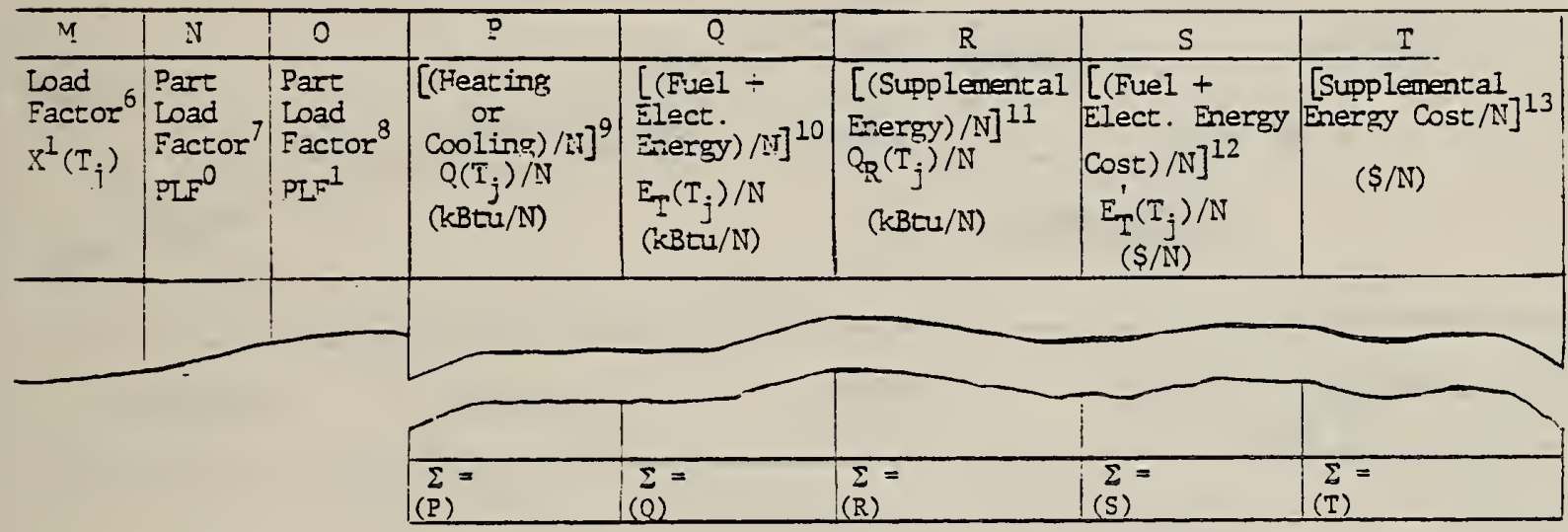

Ref. 1: Table 3 or 4

\begin{tabular}{|c|c|c|c|c|c|c|c|c|}
\hline \multirow{3}{*}{$\begin{array}{l}\text { Ref } \\
\text { :No. }\end{array}$} & \multirow{3}{*}{ Term } & \multicolumn{7}{|c|}{ Value of Equation to be used for: } \\
\hline & & \multicolumn{4}{|c|}{$\begin{array}{l}\text { Two-Speed } \\
\text { Regime }\end{array}$} & \multicolumn{3}{|c|}{$\begin{array}{l}\text { Variable-Speed } \\
\text { Regime }\end{array}$} \\
\hline & & I & II & III & IV & I & II & III \\
\hline 5 & $x^{0}\left(T_{j}\right)$ & 5.27 & 0 & 0 & 5.40 & 5.27 & 0 & -- \\
\hline 6 & $X^{1}\left(T_{j}\right)$ & 0 & 1 & 5.35 & 5.41 & 0 & 1 & -- \\
\hline 7 & PLF & 5.28 & 0 & 0 & 0 & 5.28 & 0 & -- \\
\hline 8 & PLF 1 & 0 & 1 & 5.36 & 0 & 0 & 1 & -- \\
\hline 10 & $E_{T}\left(T_{j}\right) / N$ & 5.24 & 5.29 & 5.32 & 5.37 & 5.24 & 5.29 & 5.42 \\
\hline 12 & $E_{T}^{\prime}\left(T_{j}\right) / N$ & 5.25 & 5.30 & 5.33 & 5.38 & 5.25 & 5.30 & 5.43 \\
\hline
\end{tabular}

Ref. 2: Interpolation of Test Data

Ref. 3: Use Eqn. (5.23)

Ref. 4: Regime I: $B L\left(T_{j}\right)<\dot{0}_{S S}^{0}\left(T_{j}\right)$

Regime II: $B L\left(T_{j}\right)>\dot{Q}_{S S}^{0}\left(T_{j}\right)$

Regime III or -IV: $\dot{Q}_{S S}^{0}\left(T_{j}\right)<B L\left(T_{j}\right)<\dot{Q}_{S S}^{I}\left(T_{j}\right)$

Ref. 9: $Q\left(T_{j}\right) / \mathbb{N}=(\operatorname{Col} . C)(\operatorname{Col} . J)$

Ref. 11: $Q_{R}\left(T_{j}\right) / N=(\operatorname{Col} . C)[C o l . J-C o l . E] / n_{S}$

Ref. 13: Supplemental Energy Cost $/ \mathrm{N}=\left(C_{S}\right)(\operatorname{Col} . R)$ 


\section{TABLE 8}

RATING SHEET FOR ENGINE-DRIVEN HEAT PUMP SYSTEMS

\begin{tabular}{lllll} 
ENGINE TYPE: & BRAYTON & DIESEL & RANKINE & STIRLING \\
\hline SYSTEM TYPE: & SINGLE-SPEED & TWO-SPEED & VTH \\
\hline
\end{tabular}

BUILDING APPLICATIONS: RESIDENTIAL COMMERCIAL/INDUSTRIAL

BUILDING APPLICATIONS:

CLIMATE : NORTHERN SOUTHERN

FUEL COST: $\quad$ ELECTRIC__ $\$ / k W h \quad$ ENGINE $\quad \$ / k B t u$

SUPPLEMENTAI

\begin{tabular}{|c|c|c|c|c|}
\hline PERFORMANCE PARAMETER & SYMBOL & UNITS & HEATING & COOLING \\
\hline ARI & $\dot{Q}_{s s}(95)$ & $\mathrm{kBtu} / \mathrm{hr}$ & & \\
\hline STANDARD RATING & $\dot{Q}_{s S}(47)$ & $\mathrm{kBtu} / \mathrm{hr}$ & & \\
\hline CAPACITY & $\dot{Q}_{S S}(17)$ & $\mathrm{kBtu} / \mathrm{hr}$ & & \\
\hline ARI STANDARD & $\mathrm{COP}_{\text {SS }}(95)$ & $\cdot$ & & \\
\hline COEFFICIENT OF & $\operatorname{COP}_{\text {SS }}(47)$ & - & & \\
\hline PERFORMANCE & $\operatorname{COP}_{\text {ss }}(17)$ & - & & \\
\hline
\end{tabular}

SEASONAL PERFORMANCE

FACTOR

SPF

SEASONAL COST OF
OPERATION

SOC

$\$$

FROST DEGRADATION

COEFFICIENT

$\mathrm{C}_{\text {def }}$ 


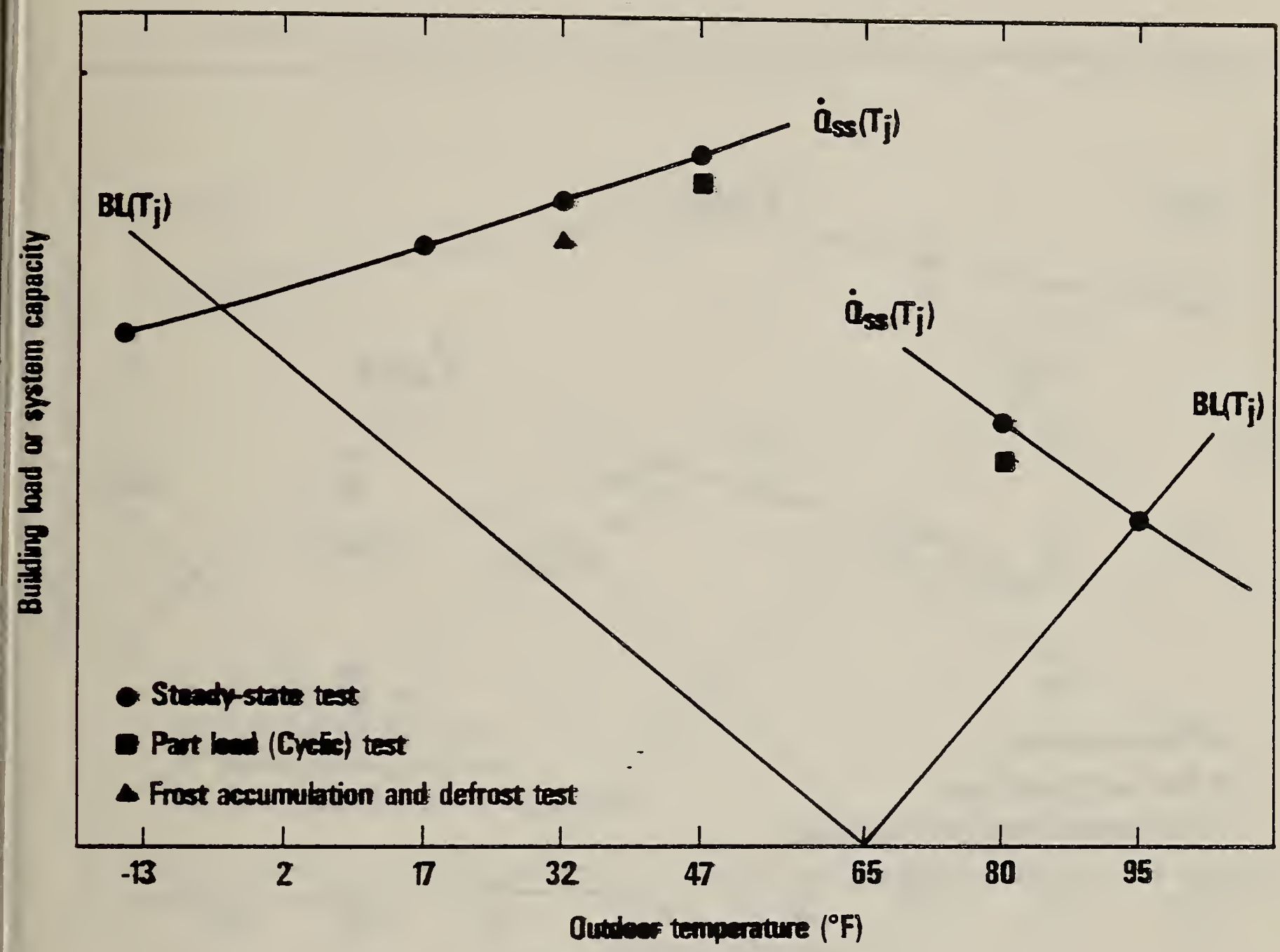

Figure 1. Test requirements for single-speed heat pump systems. 


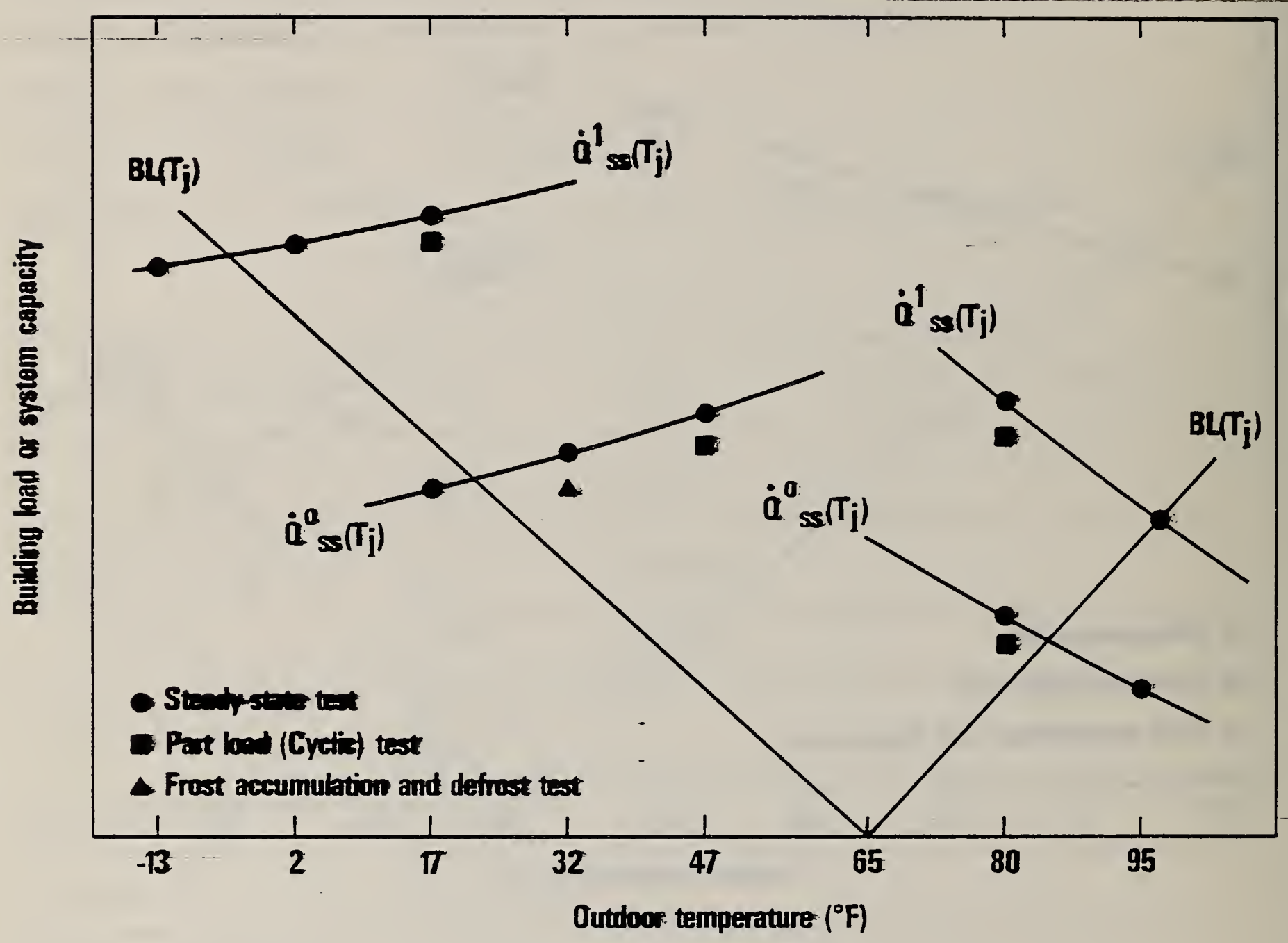

Figure 2. Test requirements for two-speed (dual capacity) heat pump systems. 


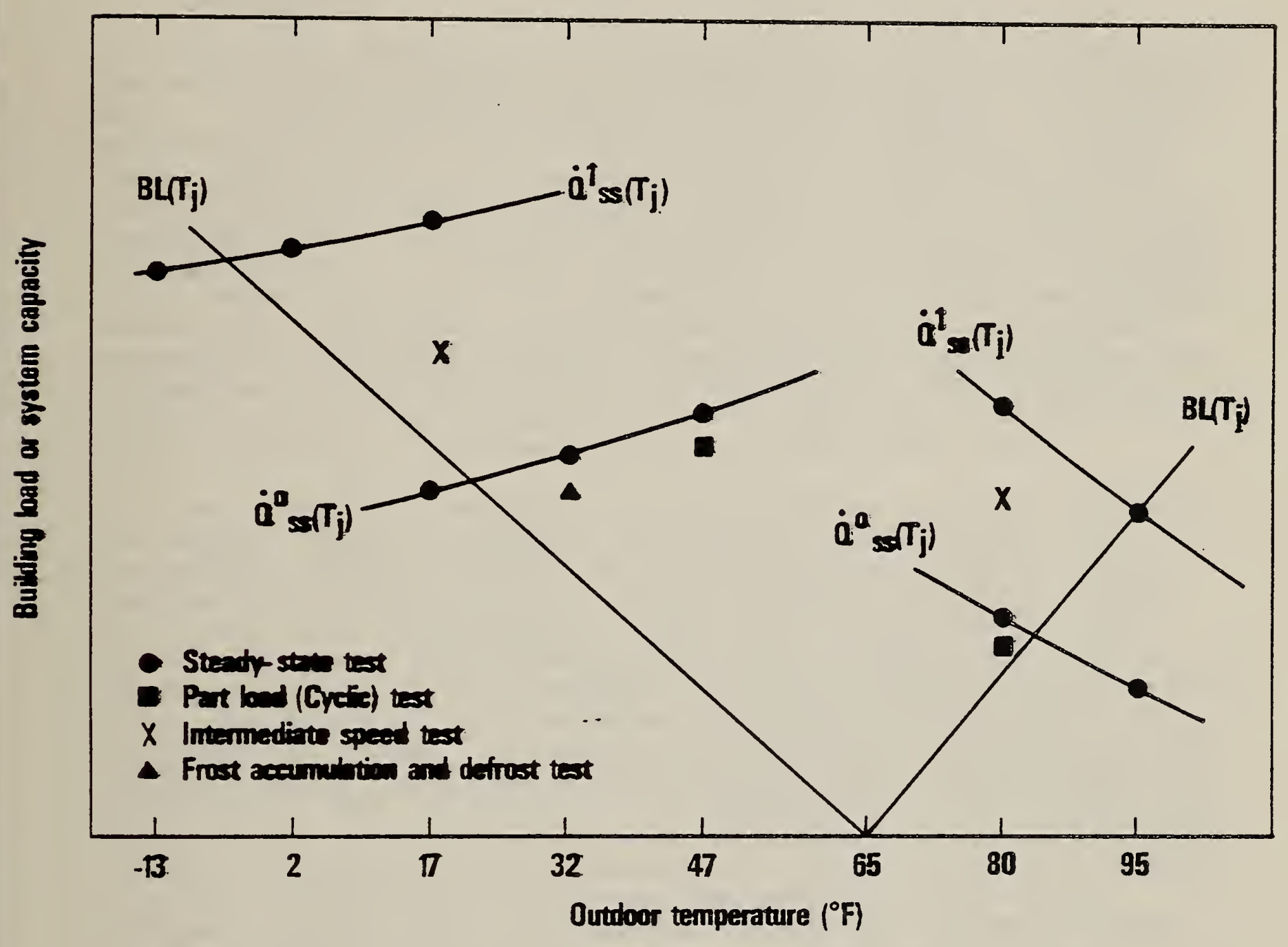

Figure 3. Test requirements for variable-speed heat pump systems. 



\title{
APPENDIX A
}

\begin{abstract}
PROPAGATION OF MEASUREMENT UNCERTAINTIES INTO THE STEADY-STATE COEFFICIENTS OF PERFORMANCE COP $S S\left(T_{j}\right)$
\end{abstract}

\section{A.1 Introduction}

Questions often arise regarding the reliability of laboratory measurements and the calculated performance of equipment which is based on these measurements. In multi-sample measurements, sufficient readings of the variable are normally taken so that reliability can be established by statistical means. Unfortunately, the time required and the operating and personnel costs of many engineering experiments are of ten too great to permit multisample measurements. The experimenter is then restricted to single-sample measurements and the questions of reliability and measurement uncertainty often become significant. This appendix will discuss valid and acceptable methods of estimating and describing the uncertainties in single-sample measurements, as well as discuss a recommended method for calculating the propagation of these uncertainties into the results. These methods will then be applied to estimating the uncertainty associated with the steadystate coefficient of performance $\mathrm{COP}_{S S}\left(T_{j}\right)$ given by eqn. $(5.2)$.

In order to eliminate confusion regarding terminology, several fundamental concepts should be reviewed. As defined in ASHRAE Standard 41.5-75, the difference between the true value of a measured quantity and the observed value of the quantity is termed the "error" of the measurement. The "accuracy" of a measurement is indicated by the size of the error, and is often termed the systematic error. This type of error persists in all repetitions of the measurement and can be corrected through calibration. The "precision" of a measurement is indicated by how sharply the measurement is defined. It is an error which causes the readings to take random values on either side of some mean value, and is often termed the random error. The "uncertainty" of the measurement is the estimated value of the error. Although the uncertainty of a measurement may reflect both accuracy and precision errors (systematic or random) we will only consider precision errors, since it is presumed that accuracy errors could be eliminated through careful calibration. A "variable" will mean a basic quantity observed in the laboratory (pressure, temperature, volume, etc.), and its recorded values or readings will be called "data". The term "result" will refer to the value obtained by making corrections to or calculations with the data. "Propagation of uncertainty" shall mean the way in which uncertainties in the variables affect the uncertainty in the results.

The conventional means for stating the uncertainty of a variable is a statement of the best estimate of the true value together with a statement about the magnitude of the error in the estimate (uncertainty). The best estimate of the true value is nomally the mean of the readings. and the uncertainty is estimated based upon specified odds (confidence level). The recommended format for describing the best value of a variable is: 


$$
V=M \pm W,(P \text { percent })
$$

where $\mathrm{V}$ is the variable, $\mathrm{M}$ is the best value, $\mathrm{W}$ is the uncertainty, and $P$ is the confidence level expressed as a percentage. The implication of eqn. ( $A 1$ ) is that the best value of $\mathrm{V}$ is $\mathrm{M}$ with a $\mathrm{P}$ percent probability that the true value lies within $\pm W$ of the value $M$. Determination of the uncertainty $W$ with a given level of confidence (given odds) is often based upon the experience and judgment of the experimenter, and is a value selected such that he would be willing to wager (with $P$ percent confidence) that the error is less than W. Eqn. (A1) provides a method by which the experimenter can describe the uncertainties associated with his basic measurements. It then becomes necessary to determine how these uncertainties propagate into the results.

If we let the result $R$ be a function of $n$ independent variables $v_{1}, v_{2}$, - $\cdot, v_{n}$, and each of the independently measured variables has an uncertainty $\Delta_{v_{1}}, \Delta_{v_{2}}, \ldots ., \Delta_{n}$, then the uncertainty in the result $\Delta \mathrm{R}$ is shown in Ref. 8 to be:

$$
\Delta R=\left[\left(\frac{\partial R}{\partial v_{1}} \Delta_{1}\right)^{2}+\left(\frac{\partial R}{\partial v_{2}} \Delta_{v_{2}}\right)^{2}+\cdots+\left(\frac{\partial R}{\partial v_{n}} \Delta_{v_{n}}\right)^{2}\right] 1 / 2
$$

The effect of large uncertainties in the variables is emphasized by this equation, and it shows that a specified reduction in a large uncertainty has a greater effect than a comparable reduction in a small uncertainty. It has been found from experience that a nondimensional form of eqn. (A2) is often more useful because it expresses the uncertainties on a percentage basis, and is generally easier to use. Dividing every term of eqn. (A2) by $\mathrm{R}$ gives:

$$
\frac{\Delta R}{R}=\left[\left(\frac{\partial R}{\partial v_{1}} \frac{\Delta v_{1}}{R}\right)^{2}+\left(\frac{\partial R}{\partial v_{2}} \frac{\Delta v_{2}}{R}\right)^{2}+\cdots+\left(\frac{\partial R}{\partial v_{n}} \frac{\Delta v_{n}}{R}\right)^{2}\right]^{1 / 2}
$$

Eqns. (A2) and (A3) are important in instrumentation selection since they show the experimenter where large uncertainties occur, and he may then improve the instrumentation or experimental techniques in these areas.

\section{A. 2 Steady-State Heating Coefficient of Performance}

The steady-state coefficient of performance $\mathrm{COP}_{S S}\left(\mathrm{~T}_{j}\right)$ of an enginedriven system is given by eqns. (5.1) and (5.2), and is repeated here for convenience: 


$$
\operatorname{COPSS}\left(T_{j}\right)=\frac{Q_{S S}\left(T_{j}\right)}{\dot{m}_{f}\left(T_{j}\right) L H V+\frac{3.413}{.3} \dot{E}_{S S}\left(T_{j}\right)}
$$

The $\operatorname{COP}_{S S}\left(T_{j}\right)$ is a function of several variables, each of which is subject to an uncertainty:

$$
\operatorname{COP}_{S S}\left(T_{j}\right)=f\left(\dot{Q}_{S S}\left(T_{J}\right), \dot{m}_{f}\left(T_{j}\right), L H V, \dot{E}_{S S}\left(T_{j}\right)\right)
$$

By forming the required derivatives $\frac{{ }^{\partial \mathrm{COP}_{S S}\left(T_{j}\right)}}{\partial \dot{Q}_{S S}\left(T_{j}\right)}, \frac{{ }^{\partial C O P_{S S}}\left(T_{j}\right)}{\partial_{\dot{m}_{f}}\left(T_{j}\right)}$,

$\frac{\partial \operatorname{COP}_{S S}\left(T_{j}\right)}{\partial L H V}$, and $\frac{\partial \operatorname{COP}_{S S}\left(T_{j}\right)}{\partial E_{S S}^{\cdot}\left(T_{j}\right)}$, substituting into eqn. (A3) and simplifying, it can be shown that:

$\frac{\Delta \operatorname{COP}_{S S}\left(T_{j}\right)}{\operatorname{COP}_{S S}\left(T_{j}\right)}=\left[\frac{\Gamma \dot{Q}_{S S}\left(T_{j}\right)}{\dot{Q}_{S S}\left(T_{j}\right)}\right]+\left[\frac{L H V \cdot \Delta_{\mathbf{m}_{f}}\left(T_{j}\right)}{\dot{m}_{f}\left(T_{j}\right) L H V+3.413 \dot{E}_{S S}\left(T_{j}\right) / .3}\right]$

$\left.+\left[\frac{\dot{m}_{f}\left(T_{j}\right) \cdot \Delta L H V}{\dot{m}_{f}\left(T_{j}\right) L H V+3.413 \dot{E}_{S S}\left(T_{j}\right) / .3}\right]^{-i}+\left[\frac{3.413 \Delta \dot{E}_{S S}\left(T_{j}\right) / .3}{\dot{m}_{f}\left(T_{j}\right) L H V+3.413 \dot{E}_{S S}\left(T_{j}\right) / .3}\right]^{2}\right]^{1 / 2}$

The term $\Delta \dot{Q}_{S S}\left(T_{j}\right) / \dot{Q}_{S S}\left(T_{j}\right)$ is determined for the heating mode with the procedure described below.

Using the appropriate equations given in ASHRAE Standard 37-69, the steady-state heating capacity $\mathrm{Q}_{S S}\left(\mathrm{~T}_{j}\right)$ is:

$$
\dot{Q}_{S S}\left(T_{j}\right)=60 \cdot 1096 C A_{n}\left[.24+.444 W_{n}\right]\left[T_{a 2}-T_{a 1}\right]\left[\frac{P_{v} P_{n}}{R_{a} T_{n}\left[1+N_{n}\right]}\right]^{1 / 2}
$$


where $C$ is the discharge coefficient of the air flow measuring nozzle, $A_{n}$ is the nozzle area in $\mathrm{ft}^{2}, \mathrm{P}_{\mathrm{n}}$ and $\mathrm{T}_{\mathrm{n}}$ are the static pressure and temperature at the nozzle throat in $i n$. Hg absolute and ${ }^{\circ} \mathrm{R}$, respectively, $\mathrm{P}_{\mathrm{v}}$ is the velocity pressure at the nozzle throat in in. $\mathrm{H}_{2} \mathrm{O}$, and $\mathrm{R}_{a}$ is the universal gas constant in units of (in. Hg $\left.-f t^{3}\right) /\left(1 b^{2}{ }^{\circ} \mathrm{R}\right)$. The remaining terms are defined in the nomenclature. Eqn. (A7) may be simplified by letting:

$$
\begin{aligned}
& k=60 \cdot 1096 \mathrm{C} \\
& \beta=T_{a 2}-T_{a 1} \\
& \alpha=\frac{.24+.444 \mathrm{~W}}{\left(1+W_{n}\right)^{1 / 2}} \\
& \theta=\left[\frac{P_{v} P_{n}}{R_{a} T_{n}}\right]^{1 / 2}
\end{aligned}
$$

$\dot{Q}_{S S}\left(T_{j}\right)$ then becomes:

$$
\dot{Q}_{S S}\left(T_{j}\right)=K A_{n} \alpha \beta \theta
$$

Letting the uncertainties associated with the parameters $A_{h}, \alpha$, $\beta$, and $\theta$ be denoted by $\Delta A_{n}, \Delta \alpha, \Delta \beta$, and $\Delta Q$, respectively, and assuming $K$ is a constant, eqn. (A3) can be used to show that the nondimensionalized uncertainty in $\dot{Q}_{S S}\left(T_{j}\right)$ is:

$$
\frac{\Delta \dot{Q}_{S}\left(T_{j}\right)}{\dot{Q}_{S S}\left(T_{j}\right)}=\left[\left[\frac{\Delta A}{A_{N}}\right]^{2}+\left[\frac{\Delta \alpha}{\alpha}\right]^{2}+\left[\frac{\Delta \beta}{\beta}\right]^{2}+\left[\frac{\Delta \theta}{\theta}\right]^{2}\right]^{1 / 2}
$$

The nondimensionalized uncertainties in $\alpha, \beta$, and $\theta$ may be determined through the use of eqns. (A8) and (A3), and are:

$$
\frac{\Delta \alpha}{\alpha}=\left[\frac{.111 \mathrm{~W}_{\mathrm{n}}+.162}{.222 \mathrm{~W}_{\mathrm{n}}^{2}+.342 \mathrm{~W}_{\mathrm{n}}+.12}\right] \Delta \mathrm{W}_{\mathrm{n}}
$$




$$
\begin{aligned}
\frac{\Delta B}{B} & =\frac{\Delta\left[\mathrm{T}_{\mathrm{a} 2}-\mathrm{T}_{\mathrm{a} 1}\right]}{\left[\mathrm{T}_{\mathrm{a} 2}-\mathrm{T}_{\mathrm{a} 1}\right]} \\
\frac{\Delta \theta}{\theta} & =\left[\frac{1}{4}\left[\frac{\Delta \mathrm{P}_{v}}{\mathrm{P}_{v}}\right]^{2}+\frac{1}{4}\left[\frac{\Delta \mathrm{P}_{n}}{P_{n}}\right]^{2}+\frac{1}{4}\left[\frac{\Delta T_{n}}{T_{n}}\right]^{2}\right]^{1 / 2}
\end{aligned}
$$

Eqns. (All to Al3) may now be substituted into eqn ( $A 10$ ) to yield $\Delta \dot{Q}_{S S}\left(T_{j}\right) / \dot{Q}_{S S}\left(T_{j}\right)$, and this in turn may be substituted into eqn. (A6) to give the final nondimensional expression for the uncertainty in the steady-state coefficient of performance. Accordingly:

$$
\begin{aligned}
& \frac{{ }_{\operatorname{COP}} S_{S}\left(T_{j}\right)}{\operatorname{COP}_{S S}\left(T_{j}\right)}=\left[\left[\frac{\Delta A_{n}}{A_{n}}\right]^{2}+\left[\frac{.111 w_{n}+.162}{.222 W_{n}^{2}+.342 w_{n}+.12}\right]^{2} \cdot \Delta W_{n}{ }^{2}\right.
\end{aligned}
$$



$$
\begin{aligned}
& +\left[\frac{\operatorname{LHV} \cdot \Delta_{\dot{\mathrm{m}}_{f}}\left(T_{j}\right)}{{\omega_{f}}_{f}\left(T_{j}\right) L H V+3.413 \dot{\varepsilon}_{S S}\left(T_{j}\right) / .3}\right]^{2} \\
& +\left[\frac{\omega_{f}\left(T_{j}\right) \cdot \Delta L H V \cdot-}{\omega_{f}\left(T_{j}\right) L H V+3.413 \dot{E}_{S S}\left(T_{j}\right) / .3}\right] \\
& \left.+\left[\frac{3.413 \Delta E_{S S}\left(T_{j}\right) / .3}{{\omega_{f}}_{f}\left(T_{j}\right) L H V+3.413 \dot{E}_{S S}\left(T_{j}\right) / .3}\right]^{2}\right]^{1 / 2}
\end{aligned}
$$

Eqn. (A14) shows that the uncertainty in $\operatorname{COP}_{S S}\left(T_{j}\right)$ is a function of nine measured parameters, each with its own measurement uncertainty. Therefore, 
$\operatorname{COP}_{S S}\left(T_{j}\right)=f\left(A_{n}, W_{n}, T_{a 2}-T_{a 1}, P_{v}, P_{n}, T_{n}, \dot{m}_{f}\left(T_{j}\right), L H V, \dot{E}_{S S}\left(T_{j}\right)\right)$.

\section{A.3 Sample Calculation}

As an illustration of the previous concepts, consider the following example taken from the experimental results of a Stirling engine-driven heat pump system operating at an outdoor temperature of $50^{\circ} \mathrm{F}$. The measured values of the variables required in eqn. (A4) are:

$$
\begin{aligned}
& \dot{Q}_{S S}(50)=67,800 \mathrm{Btuh} \\
& \dot{\mathrm{m}}_{\mathrm{f}}(50)=2.441 \mathrm{bm} / \mathrm{hr} \\
& \mathrm{LHV}=19,930 \mathrm{Btu} / 1 \mathrm{bm} \\
& \dot{\mathrm{E}}_{\mathrm{SS}}\left(\mathrm{T}_{j}\right)=820 \mathrm{~W}
\end{aligned}
$$

Substitution into eqn. (A4) yields $\operatorname{COP}_{\mathrm{SS}}(50)=i .17$ as the calculated result. The uncertainty in this result is given by eqn. (A14). The uncertainties of the individual measurements were estimated with a $95 \%$ confidence level ( 19 to 1 odds) to be:

$$
\begin{aligned}
\frac{\Delta A_{n}}{A_{n}} & =0.01(.1 \%) \\
\Delta W_{n} & =3.5 \times 10^{-5} 1 \mathrm{bm} \text { moisture per 1bm dry air }
\end{aligned}
$$

$$
\begin{aligned}
\frac{\Delta\left[\mathrm{T}_{\mathrm{a} 2}-\mathrm{T}_{\mathrm{al}}\right]}{\left[\mathrm{T}_{\mathrm{a} 2}-\mathrm{T}_{\mathrm{al}}\right]} & =0.01(1 \%) \\
\frac{\Delta \mathrm{P}_{\mathrm{v}}}{\mathrm{P}_{\mathrm{v}}} & =0.005(0.5 \%) \\
\frac{\Delta \mathrm{P}_{\mathrm{n}}}{\mathrm{P}_{\mathrm{n}}} & =0.01(1 \%) \\
\frac{\Delta \mathrm{T}_{\mathrm{n}}}{\mathrm{T}_{\mathrm{n}}} & =0.005(0.5 \%) \\
\Delta \text { Hf }_{\mathrm{f}}\left(\mathrm{T}_{j}\right) & =.02441 \mathrm{bm} / \mathrm{hr}(1 \%) \\
\Delta \mathrm{LHV} & =100 \mathrm{Btu} / 1 \mathrm{bm}(0.5 \%) \\
\Delta \dot{\mathrm{E}}_{\mathrm{SS}}\left(\mathrm{T}_{\mathrm{J}}\right) & =8 \mathrm{~W}(1 \%)
\end{aligned}
$$


MBS- ITAA (REV. 0.78)

U.S. DEPT. OF COMM.

BIBLIOGRAPHIC DATA SHEET

1. PUBLICATION OR REPORT NO.

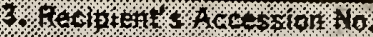

NBSIR 79-1911

4. TITLE AND SUBTITLE

PROCEDURES FOR TESTING, RATING, AND ESTIMATING THE SEASONAL PERFORMANCE OF ENGINE-DRIVEN HEAT PUMP SYSTEMS

5. Publication Date

September 1979

7. AUTHOR(S)

Dr. Barry R. Maxwell

9. PERFORMING ORGANIZATION NAME AND ADDRESS

NATIONAL BUREAU OF STANDARDS

DEPARTMENT OF COMMERCE

WASHINGTON, DC 20234

12. SPONSORING ORGANIZATION NAME AND COMPLETE ADDRESS (streot, City, State, zIP)

The Department of Energy

20 Massachusetts Ave., NW

Washington, D.C. 20545

14. Sponsoning Agency Code

15. SUPPLEMENTARY NOTES

Dr. Maxwell conducted this study during a year in residence at NBS under the IPA (Intergovernment Personnel Act) program.

$\square$ Document describes a computer program; SF-185, FIPS Software Summary, is attached.

16. ABSTRACT (A 200-word or less factual summary of most significant information. If document includes a significant bibliography or literature survey, mention it here.)

A generic test and rating procedure is developed for heat engine-driven air-to-air heat pump systems. The procedures are classified according to whether the systems have single-speed, two-speed, or variable-speed capability, and whether they are operating in the heating or cooling mode. The test requirements generally consist of a series of steady-state tests to establish the impact of outdoor temperature on performance, two or more part-load (cyclic) tests to determine the effect of "on-off" cycling, two steady-state intermediate speed tests to determine part-speed performance, and a single frost accumulation test to estimate the effect of frost. A generalized calculation and rating procedure is developed. The system is rated in both modes based upon its steady-state performance at the ARI standard rating points, its seasonal performance factor, and its seasonal operating cost. A frost degradation coefficient is also established. The seasonal parameters are based upon either a residential or commercial/industrial building application which is located in either a generalized northern or southern climate.

17. KEY WORDS (six to twelve entries; alphabetical order; capitalize only the first letter of the first key word unless a proper name; soparated by semicolons)

Building heating and cooling; engine-driven heat pump; heat pump; heating and cooling equipment; heating, ventilating and air conditioning.

18. AVAILABILITY

X Unlimited

For Official Distribution. Do Plot Release to NTIS

Order From Sup. of Doc., U.S. Government Printing Office, Washington, DC 20402, SD Stock No. SNOD3-003-

Order From National Technical Information Service (NTIS), Springfield, VA. 22161

\begin{tabular}{|l|l|}
$\begin{array}{l}\text { 19. SECURITY CLASS } \\
\text { (THIS REPORT) }\end{array}$ & $\begin{array}{l}\text { 21. NO. OF } \\
\text { PRINTED PAGES } \\
\text { UNCLASSIFIED }\end{array}$ \\
\hline $\begin{array}{l}\text { 20. SECURITY CLASS } \\
\text { (THIS PAGE) } \\
\text { UNCLASSIFIED }\end{array}$ & 22. Price \\
\hline
\end{tabular}




\section{2}

